Research Article

\title{
Effectiveness and Safety of Oral Chinese Patent Medicines Combined with Chemotherapy for Gastric Cancer: A Bayesian Network Meta-Analysis
}

\author{
Xiaona Lu $\mathbb{D}^{1},{ }^{1}$ Yawei Zheng, ${ }^{1}$ Fang Wen, ${ }^{1}$ Wenjie Huang, ${ }^{1}$ and Peng Shu $\mathbb{D}^{2}$ \\ ${ }^{1}$ First School of Clinical Medicine, Nanjing University of Chinese Medicine, Nanjing 210029, China \\ ${ }^{2}$ Oncology Department, Jiangsu Province Hospital of Chinese Medicine, Nanjing 210029, China \\ Correspondence should be addressed to Peng Shu; shupengsp@njucm.edu.cn
}

Received 6 March 2020; Revised 22 May 2020; Accepted 9 June 2020; Published 26 August 2020

Academic Editor: Mohammed S. Ali-Shtayeh

Copyright (c) 2020 Xiaona Lu et al. This is an open access article distributed under the Creative Commons Attribution License, which permits unrestricted use, distribution, and reproduction in any medium, provided the original work is properly cited.

Objectives. This network meta-analysis (NMA) was designed to assess the comparative effectiveness and safety of oral Chinese patent medicines combined with chemotherapy for gastric cancer on the National Basic Medical Insurance Drugs List of China. Methods. A comprehensive literature search was performed in seven electronic databases from their inception to February 25, 2020, aiming to collect all related randomized controlled trials (RCTs) to evaluate the effectiveness and safety of oral Chinese patent medicines as an adjuvant for gastric cancer. Two researchers independently screened the literature, extracted data, and assessed the risk of bias of included studies using the Cochrane Risk of Bias Scale. NMA was then performed by using STATA 16.0 software and ADDIS 1.16 .8 software. Results. Finally, 30 RCTs were included, involving seven kinds of oral Chinese patent medicines, with a total of 2602 patients. For improvement of clinical efficacy, Bazhen granule combined with chemotherapy was ranked first for effectiveness, followed by the Cinobufacin capsule combined with chemotherapy and Xiao'aiping tablet combined with chemotherapy. Meanwhile, Bazhen granules combined with chemotherapy also were ranked first in reducing gastrointestinal reactions. In terms of improving performance status, the Xiao'aiping tablet was the best and significantly better than other oral Chinese patent medicines. Besides, the Zhenqi Fuzheng granule combined with chemotherapy was best for reducing the incidence of leucopenia. Conclusions. Since only one RCT of Bazhen granule was included in this study for analysis, its statistical efficiency is low. Therefore, this study recommends that the Cinobufacin capsule combined with chemotherapy should be a priority in improving clinical efficacy. In terms of improving patients' quality of life, Xiao'aiping tablet is the best choice. Safety was best for Zhenqi Fuzheng granule and Bazhen granule combined with chemotherapy. Limited by the quantity, quality, and possible bias of included studies, the above conclusions need to be further verified by more high-quality RCTs.

\section{Introduction}

Gastric cancer is one of the leading causes of cancer-related death worldwide, and its incidence is sixth in the world's cancer. China is a country with a high incidence of gastric cancer, and China accounts for nearly half the world's gastric cancer burden [1]. According to the statistics of China National Cancer Center, gastric cancer ranks among the top three in terms of morbidity and mortality and is a malignant tumour with serious harm [2]. At present, surgery is considered to be the only radical treatment. However, gastric cancer has the characteristics of high incidence, a high metastatic rate, high mortality, low early diagnosis rate, low radical resection rate, and low five-year survival rate. Therefore, chemotherapy plays a vital role in prolonging the survival time of gastric cancer patients [3]. Although chemotherapy can extend the survival period of patients, its adverse reactions also seriously affect the quality of life of patients and are even challenging to tolerate chemotherapy. Traditional Chinese medicine (TCM) has been used to treat cancer for thousands of years. As an essential part of complementary and alternative therapy, it has become one of the vital means of comprehensive treatment of gastric cancer. In recent years, researches on the treatment of gastric 
cancer with TCM have shown that it has the effects of improving clinical efficacy, resisting recurrence and metastasis, improving quality of life, reducing toxic and side effects of radiotherapy, and chemotherapy and enhancing immunity [4]. Therefore, TCM adjuvant therapy is of considerable significance in improving the constitution of gastric cancer patients, improving the completion rate and efficiency of chemotherapy, etc. Besides, compared with Chinese herbal pieces, oral Chinese patent medicine has the advantages of convenient administration and accurate dosage, which have been widely used in clinical trials. Oral Chinese patent medicine can often play a better role in the treatment of gastric cancer, which can be used in combination with chemotherapy for patients in generally good condition. In contrast, for patients without chemotherapy indications, it can be used alone to achieve the purpose of disease control. Also, some adjuvant oral Chinese patent medicines can be used to relieve various discomfort symptoms of gastric cancer patients, such as pain, belching, acid reflux, hematochezia, and emaciation and can reduce the adverse reactions after chemotherapy and improve the immunity of patients to improve the quality of life of gastric cancer patients [5].

As an extension of traditional meta-analysis, network meta-analysis has the advantage of combining multiple processing and indirect comparison evidence, ranking the sufficient probability of interventions, and providing more comprehensive and valuable information for clinical decision-making [6]. Although many trials have compared the efficacy and safety of oral Chinese patent medicine in the treatment of gastric cancer, there is a lack of head-to-head comparisons between different oral Chinese patent medicines, and its relative advantages have not been well understood. Therefore, to confirm the best therapy, this study uses NMA to compare the efficacy and safety of multiple oral Chinese patent medicines combined with chemotherapy in the treatment of gastric cancer, aiming to provide evidencebased medicine basis for clinical decision-making.

\section{Materials and Methods}

This NMA was conducted by the PRISMA NMA Statement [7]. A completed PRISMA 2015 network meta-analysis checklist was included as supplementary material (Table S1).

\subsection{Eligibility Criteria}

2.1.1. Types of Studies. Studies included are randomized controlled trials (RCTs), regardless of blinding. The languages are limited to Chinese and English.

2.1.2. Types of Participants. Patients with definite pathological diagnosis of gastric cancer have unlimited stages, age $\geq 18$ years old, no limitation of gender, race, nationality, etc. There is at least one measurable clinical or imaging observation index, with Karnofsky (KPS) score $\geq 60$ or Eastern Cooperative Oncology Group (ECOG) score of 0-2. There is no chemotherapy contraindication before treatment, and there is no obvious abnormality in liver and kidney function, haematology, and electrocardiograph (ECG).

2.1.3. Types of Interventions. Interventions involving oral Chinese patent medicines combined with chemotherapy for the treatment of gastric cancer are eligible. The control groups include chemotherapy alone or another oral Chinese patent medicine combined with chemotherapy. These oral Chinese patent medicines are recommended by the Clinical Practice Guidelines of Chinese Medicine in Oncology and included in the National Basic Medical Insurance Drugs List of China, specifically Bailing capsule, Jianpi Yishen granule, Zhenqi Fuzheng capsule/granule/tablet, Bazhen granule/ capsule/pill/tablet, Buzhong Yiqi pill, Shiquan Dabu pill, Xiao'aiping tablet/capsule/drop pill, Cinobufacin tablet/ capsule, Antike capsule, Pingxiao capsule/tablet, Andolin capsule, Yangyin Shengxue mixture, Shiyiwei Shengqi tablet/capsule, Shenqi Shiyiwei granule, and Kanglaite soft capsule [8].

2.1.4. Types of Outcome Measures. The primary effectiveness outcome was the objective response rate (ORR). ORR was evaluated according to Response Evaluation Criteria in Solid Tumors (RECIST 1.1) [9]. ORR $=$ [Complete Response (CR) + Partial Response (PR) ]/total cases $\times 100 \%$. The secondary outcome was performance status. Performance status was assessed by the Karnofsky (KPS) score. After treatment, the KPS score increased by more than 10 points was considered effective. The safety outcome was adverse drug reactions (ADRs) involving the incidence of leucopenia and gastrointestinal reaction. The incidence of $\mathrm{ADRs}=$ number of ADRs/total cases $\times 100 \%$.

2.2. Exclusion Criteria. (1) It was associated with any other primary tumours, such as lung cancer; (2) it was combined with other interventions, such as acupuncture and other traditional Chinese medicine treatments; (3) it was repeatedly published literature; (4) no valid data were reported for analysis or the data were not credible.

2.3. Information Sources and Search. We searched in seven electronic databases including the Cochrane Library, PubMed, Embase, China National Knowledge Infrastructure (CNKI), WanFang Data, China Science and Technology Journal Database (CSTJ), and China Biology Medicine disc (CBMdisc) from their inception to February 25, 2020, to collect RCTs of oral Chinese patent medicine combined with chemotherapy in the treatment of gastric cancer. The search is carried out by the combination of subject words and free words. Search terms include "stomach neoplasms," "gastric cancer," "stomach cancer," "medicine" (name of each oral Chinese patent medicine), and "randomized controlled trial”. Taking PubMed as an example, its specific search strategy is shown in Table S2. 
2.4. Study Selection and Data Extraction. Endnote X9 software was used to manage literature and delete duplicate literature. Then, two researchers independently screened literature, extracted data, and cross-checked them according to the eligibility criteria. After removing the apparently unrelated studies by reading the title, further, they read the abstract and the full text to determine whether to include the remaining studies. If there are differences in the implementation process, they shall be solved through discussion or consultation with the tutor.

The data of included studies were extracted into the designed Microsoft Excel sheet, containing the first author, publication year, sample size, baseline characteristics (TNM stage, sex, age), intervention measures, course of treatment, and outcomes.

2.5. Risk of Bias within Individual Studies. Two researchers assessed the risk of bias within individual studies independently by using the Cochrane Risk of Bias (Scale) [10]. The items mainly include the following seven aspects: (1) random sequence generation (selection bias), (2) allocation concealment (selection bias), (3) blinding of participants and personnel (performance bias), (4) blinding of outcome assessment (detection bias), (5) incomplete outcome data (attrition bias), (6) selective reporting (reporting bias), and (7) other biases. The evaluation level of bias risk is split into "low risk," "unclear risk," and "high risk." If there gets some inconsistency, it shall be solved through collective discussion or consultation with the tutor.

2.6. Statistical Analysis. Review Manager 5.3 software, STATA 16.0 software, and Aggregate Data Drug Information System (ADDIS) 1.16.8 software were used for statistical analysis. In this study, outcome data types are all dichotomous variables, so the odds ratio (OR) and its 95\% confidence interval (CI) were used as the effect. Review Manager 5.3 was used for literature quality evaluation. Stata 16.0 software was used to analyse the heterogeneity and draw the evidence network graph of each outcome. In the network graph, the size of treatment nodes reflects the number of patients randomly allocated to each treatment, and the thickness of edges represents the number of studies underlying each comparison; A comparison-adjusted funnel plot was made to evaluate whether there was a publication bias in the study.

The heterogeneity between the results of each direct comparison was analysed by the chi-square test (the test level was $\alpha=0.1$ ). And the size of heterogeneity was quantitatively determined by combining with $I^{2} . I^{2} \leq 50 \%$, indicating that the heterogeneity between the research results is small, and the fixed-effect model was used for meta-analysis; otherwise, the heterogeneity is considerable; on the premise of excluding clinical heterogeneity, the random effect model can be used for meta-analysis [11]. Apparent clinical heterogeneity was treated by subgroup analysis or sensitivity analysis or only descriptive analysis. When there is a closedloop structure between the interventions, it is necessary to perform the inconsistency test. Judging by the inconsistency factor (IF), when the IF value 95\% CI contains 0 , it means that the direct evidence is consistent with the indirect evidence.

ADDIS 1.16.8 software which is based on the Bayesian framework using the Markov chain Monte Carlo (MCMC) method for prior assessment and implementation was used for the network meta-analysis [12]. Four Markov chains are used to set the initial value. The variance scaling factor of the model is 2.5, the thinning interval is 10 , the tuning iterations are 20000, and the simulation iterations are 50000. When the potential scale reduced factor (PSRF) tends to 1, the convergence degree is satisfied. Finally, the results of network meta-analysis are presented in tabular form, and the probability of each intervention becoming the best one is offered by ranking probability.

\section{Results}

3.1. Study Selection and Study Characteristics. According to the search strategy of this study, a total of 954 related studies were obtained in the initial examination, and 30 RCTs were included in quantitative synthesis ultimately [13-42]. The PRISMA flow diagram of studying selection is shown in Figure 1.

There were 2602 patients in 30 studies, involving seven kinds of oral Chinese patent medicines, namely, Antike capsule (ATK), Bazhen granule (BZ), Shenqi Shiyiwei granule (SQSYW), Cinobufacin capsule (HCS), Pingxiao capsule (PX), Xiao'aiping tablet (XAP), and Zhenqi Fuzheng granule (ZQFZ). The number of RCTs related to these medicines was $1,1,1,12,6,5$, and 4 , respectively. The experimental group contained 1342 cases, and the control group 1260 cases. Male patients accounted for $59.6 \%$, and female patients accounted for $40.4 \%$. All the studies reported the tumour-node-metastasis (TNM) stages and ages. There were 26 (86.7\%), 13 (43.3\%), 14 $(46.7 \%)$, and $22(73.3 \%)$ studies reported the ORR, KPS, leucopenia, and gastrointestinal reaction, respectively. Details of study characteristics are shown in Table 1 . The network graph of 4 outcomes is presented in Figure 2. Since no closed loop is formed in each network graph, inconsistencies are not tested.

3.2. Risk of Bias within Studies. In terms of random sequence generation, 12 of 30 studies used reasonable methods to generate the random sequence, including random number table, coin toss, and computer-generated random numbers, which were evaluated as "low risk of bias." However, two studies were grouped by treatments, which were "high risk of bias," and the rest mentioned only random sequences, which were "unclear risk of bias." In terms of allocation concealment, only 1 study mentioned the use of orderly sealed envelope for allocation concealment, which was "low risk of bias," and the other studies did not report the information of allocation concealment. None of the studies mentioned the information on blinding. All of the studies reported complete outcome data and belonged to a "low risk of bias." 


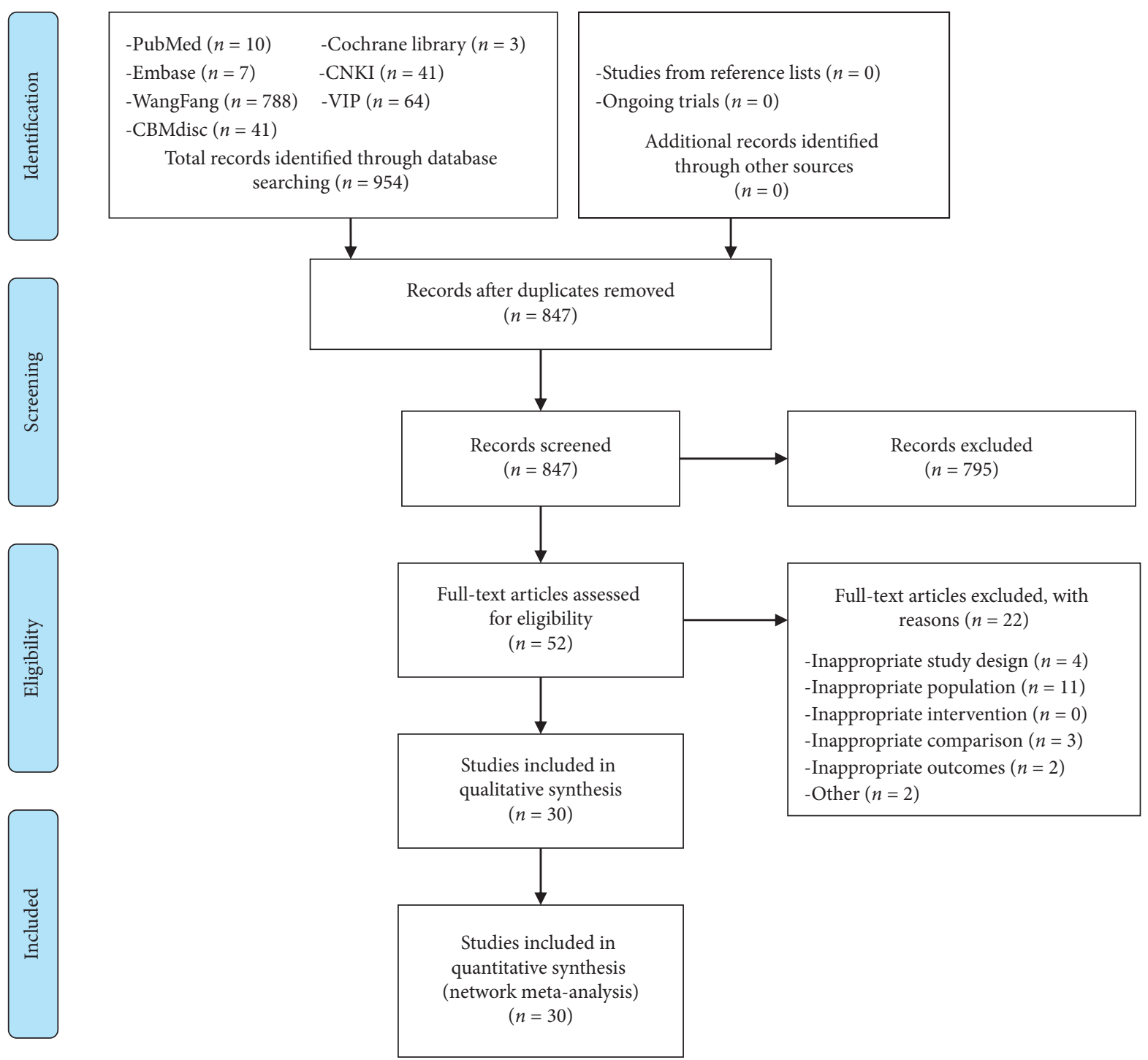

FIgUre 1: The PRISMA flow diagram of study selection ( $n$ : number of articles; CNKI: the China National Knowledge Infrastructure Database; WanFang: the WanFang Database; CSTJ: the China Science and Technology Journal Database; CBMdisc: the China Biology Medicine disc).

Whether there are selective reporting results and other biases in all studies, which could not be clearly judged according to the literature information, belongs to "unclear risk of bias." The results of bias risk assessment for all included studies are presented in Figure 3.

3.3. Results of the Meta-Analysis. The following $\mathrm{C}$ represents chemotherapy to simplify the expression of the results.

3.3.1. Objective Response Rate. The results of the heterogeneity test showed that the heterogeneity between the 26 studies was small $\left(P=0.671, I^{2}=0.0 \%\right)$, and $I^{2}$ in each subgroup was all less than $50 \%$. The results of the metaanalysis of the fixed-effect model showed that the effective rate of $\mathrm{BZ}+\mathrm{C}, \mathrm{HCS}+\mathrm{C}, \mathrm{PX}+\mathrm{C}, \mathrm{XAP}+\mathrm{C}$, and $\mathrm{ZQFZ}+\mathrm{C}$ in the treatment of gastric cancer was significantly higher than that of chemotherapy alone $(P<0.05)$, but there was no significant difference between ATC $+\mathrm{C}$, SQSYW $+\mathrm{C}$, and chemotherapy alone, as shown in Figure 4.

3.3.2. Performance Status. The results of the heterogeneity test showed that the heterogeneity between 13 studies was relatively small $\left(P=0.176, I^{2}=26.6 \%\right)$, and $I^{2}$ in each subgroup was also less than $50 \%$. The results of the metaanalysis of the fixed-effect model showed that $\mathrm{ATC}+\mathrm{C}$, $\mathrm{HCS}+\mathrm{C}, \mathrm{PX}+\mathrm{C}, \mathrm{XAP}+\mathrm{C}$, and $\mathrm{ZQFZ}+\mathrm{C}$ could significantly improve the quality of life of patients with gastric cancer compared with chemotherapy alone $(P<0.05)$, while SQSYW + C had no significant difference compared with chemotherapy alone, as shown in Figure 5.

3.3.3. ADRs. (1) Leucopenia. The results of the heterogeneity test showed that the heterogeneity among 14 studies was small $\left(P=0.385, I^{2}=6.1 \%\right)$, but $I^{2}>50 \%$ in the XAP +C 
TABLE 1: The basic characteristics of the included studies.

\begin{tabular}{|c|c|c|c|c|c|c|c|c|}
\hline \multirow{2}{*}{ Study ID } & \multirow{2}{*}{$\begin{array}{l}\text { TNM } \\
\text { stages }\end{array}$} & \multirow{2}{*}{$\begin{array}{c}\text { Sample } \\
\text { size }(\mathrm{E} / \mathrm{C})\end{array}$} & \multirow{2}{*}{$\begin{array}{l}\text { Sex, } \\
\text { M/F }\end{array}$} & \multirow{2}{*}{ Age $(\mathrm{E} / \mathrm{C})$} & \multicolumn{2}{|c|}{ Intervention } & \multirow{2}{*}{$\begin{array}{l}\text { Course } \\
(\mathrm{d} \times \mathrm{c})\end{array}$} & \multirow{2}{*}{ Outcomes } \\
\hline & & & & & E & $\mathrm{C}$ & & \\
\hline $\begin{array}{l}\text { Hong } \\
\text { et al. [13] }\end{array}$ & III $\sim \mathrm{IV}$ & $60 / 60$ & $79 / 41$ & $58.0 / 56.5$ & ATK $0.44 \mathrm{~g}, \mathrm{tid}+\mathrm{SOX}$ & SOX & $\geq 21 \mathrm{~d} \times 2$ & (1) (2) \\
\hline $\begin{array}{l}\text { Qian and } \\
\text { Zuo [14] }\end{array}$ & III IV & $40 / 40$ & $59 / 21$ & $\begin{array}{l}62.5(19 \sim 74) / \\
62(38 \sim 77)\end{array}$ & $\begin{array}{c}\text { BZ } 3.5 \text { g, bid + 5- } \\
\mathrm{Fu}+\mathrm{THP}+\mathrm{L}-\mathrm{OHP}\end{array}$ & $5-\mathrm{Fu}+\mathrm{THP}+\mathrm{L}-\mathrm{OHP}$ & $21 \mathrm{~d} \times 3$ & (1) (3) (4) \\
\hline $\begin{array}{l}\text { Zhu et al. } \\
{[15]}\end{array}$ & III IV & $27 / 27$ & $36 / 18$ & $\begin{array}{l}61(19 \sim 73) / \\
58(24 \sim 75)\end{array}$ & SQSYW 2g, tid + EOX & EOX & $\geq 21 \mathrm{~d} \times 2$ & (1) (2) (3) (4) \\
\hline $\begin{array}{l}\text { Guo et al. } \\
{[16]}\end{array}$ & III IV & $42 / 38$ & $40 / 40$ & $\begin{array}{c}66.4 \pm 4.2 / \\
64.8 \pm 3.7\end{array}$ & HCS 0.9 g,qid + FOLFOX6 & FOLFOX6 & $21 \mathrm{~d} \times 6$ & (1) \\
\hline $\begin{array}{l}\text { Zha and } \\
\text { Hang } \\
{[17]}\end{array}$ & III IV & $20 / 20$ & $24 / 16$ & $50 \sim 72$ & $\begin{array}{c}\text { HCS } 0.5 \mathrm{~g} \text {,tid + oxaliplatin } \\
130 \mathrm{mg} / \mathrm{m}^{2}+\text { Tegafur } \\
600 \mathrm{mg} / \mathrm{m}^{2}+\text { CF } 200 \mathrm{mg} / \mathrm{m}^{2}\end{array}$ & $\begin{array}{c}\text { Oxaliplatin } 130 \mathrm{mg} / \\
\mathrm{m}^{2}+\text { Tegafur } 600 \mathrm{mg} / \\
\mathrm{m}^{2}+\mathrm{CF} 200 \mathrm{mg} / \mathrm{m}^{2}\end{array}$ & $21 \mathrm{~d} \times 6$ & (1) (3) (4) \\
\hline $\begin{array}{l}\text { Lu et al. } \\
{[18]}\end{array}$ & III IV & $30 / 30$ & $23 / 37$ & $\begin{array}{l}73.7 \pm 5.1 / \\
74.8 \pm 6.2\end{array}$ & $\begin{array}{c}\text { HCS } 0.5 \mathrm{~g} \text {, tid + capecitabine } \\
1250 \mathrm{mg} / \mathrm{m}^{2}\end{array}$ & $\begin{array}{c}\text { Capecitabine } 1250 \mathrm{mg} / \\
\mathrm{m}^{2}\end{array}$ & $\geq 21 \mathrm{~d} \times 2$ & (1) (2) (3) (4) \\
\hline Ren [19] & III IV & $47 / 47$ & $54 / 40$ & $\begin{array}{c}51.24 \pm 3.98 / \\
50.15 \pm 3.87\end{array}$ & HCS $0.5 \mathrm{~g}$, tid + SOX & SOX & $21 \mathrm{~d} \times 2$ & (1) (2) (4) \\
\hline $\begin{array}{l}\text { Wu et al. } \\
{[20]}\end{array}$ & IV & $25 / 25$ & $27 / 23$ & $\begin{array}{l}59.14 \pm 4.37 / \\
58.57 \pm 4.23\end{array}$ & HCS $0.5 \mathrm{~g}$, tid + XELOX & XELOX & $21 \mathrm{~d} \times 2$ & (1) (4) \\
\hline $\begin{array}{l}\text { Yan et al. } \\
{[21]}\end{array}$ & IIIB IV & $35 / 35$ & $38 / 32$ & $\begin{array}{l}49.5 \pm 6.4 / \\
48.76 \pm 6.5\end{array}$ & $\begin{array}{c}\text { HCS } 0.9 \mathrm{~g}, \text { tid + oxaliplatin } \\
85 \mathrm{mg} / \mathrm{m}^{2}+\text { capecitabine } \\
1000 \mathrm{mg} / \mathrm{m}^{2}\end{array}$ & $\begin{array}{c}\text { Oxaliplatin } 85 \mathrm{mg} / \\
\mathrm{m}^{2}+\text { capecitabine } \\
1000 \mathrm{mg} / \mathrm{m}^{2}\end{array}$ & $21 \mathrm{~d} \times 6$ & (1) (2) (3) (4) \\
\hline Ling [22] & III IV & $48 / 48$ & $61 / 35$ & $\begin{array}{c}54.27 \pm 7.92 / \\
55.03 \pm 7.51\end{array}$ & HCS $0.9 \mathrm{~g}$, tid + FOLFOX 4 & FOLFOX4 & $14 \mathrm{~d} \times 3$ & (1) (2) (3) (4) \\
\hline $\begin{array}{l}\text { Xu and } \\
\text { Liu [23] }\end{array}$ & III IV & $30 / 30$ & $32 / 28$ & $\begin{array}{l}\text { 45. } 8(36 \sim 70) / \\
\text { 49. } 9(37 \sim 70)\end{array}$ & $\begin{array}{c}\text { HCS } 0.9 \mathrm{~g}, \mathrm{tid}+\mathrm{L}-\mathrm{OHP} \\
130 \mathrm{mg} / \mathrm{m}^{2}+5-\mathrm{FU} 300 \mathrm{mg} / \\
\mathrm{m}^{2}+\mathrm{CF} 200 \mathrm{mg} / \mathrm{m}^{2}\end{array}$ & $\begin{array}{c}\mathrm{L}-\mathrm{OHP} 130 \mathrm{mg} / \mathrm{m}^{2}+5- \\
\text { FU } 300 \mathrm{mg} / \mathrm{m}^{2}+\mathrm{CF} \\
200 \mathrm{mg} / \mathrm{m}^{2}\end{array}$ & $\geq 21 \mathrm{~d} \times 2$ & (1) (3) (4) \\
\hline $\begin{array}{l}\text { Yang and } \\
\text { Zhang } \\
{[24]}\end{array}$ & IV & $25 / 25$ & $35 / 15$ & $\begin{array}{l}54(31 \sim 75) / \\
50(37 \sim 70)\end{array}$ & HCS $0.5 \mathrm{~g}$,tid + EOF & EOF & $\geq 21 \mathrm{~d} \times 2$ & (1) (2) (3) (4) \\
\hline $\begin{array}{l}\text { Li et al. } \\
{[25]}\end{array}$ & III IV & $30 / 30$ & $38 / 22$ & $\begin{array}{l}61.5 \pm 9.0 / \\
60.8 \pm 8.8\end{array}$ & HCS $0.9 \mathrm{~g}$, tid + SOX & SOX & $21 \mathrm{~d} \times 2$ & (1) (4) \\
\hline Cao [26] & NR & $41 / 41$ & $44 / 38$ & $\begin{array}{c}54.8 \pm 5.4 / \\
56.3 \pm 4.6\end{array}$ & $\begin{array}{c}\text { HCS } 0.9 \mathrm{~g}, \operatorname{tid}+\mathrm{S}-160 \mathrm{mg} / \\
\mathrm{m}^{2}\end{array}$ & $\mathrm{~S}-160 \mathrm{mg} / \mathrm{m}^{2}$ & $28 \mathrm{~d} \times 2$ & (1) (2) \\
\hline $\begin{array}{l}\text { Wang } \\
\text { and et al. } \\
{[27]}\end{array}$ & NR & $58 / 58$ & $59 / 57$ & 58. $4 / 58.8$ & $\begin{array}{c}\text { HCS } 0.5 \mathrm{~g}, \mathrm{tid}+\mathrm{S}-180 \mathrm{mg} / \\
\mathrm{m}^{2}\end{array}$ & $\mathrm{~S}-180 \mathrm{mg} / \mathrm{m}^{2}$ & $21 \mathrm{~d} \times 2$ & (1) (2) (4) \\
\hline $\begin{array}{l}\text { Chen } \\
\text { et al. [28] } \\
\text { Que and }\end{array}$ & $\mathrm{I} \sim \mathrm{IV}$ & $33 / 33$ & $36 / 30$ & 48.8 & PX $1.15 \sim 1.84 \mathrm{~g}$, tid + ELF & ELF & $21 \mathrm{~d} \times 2$ & (1) (2) (4) \\
\hline $\begin{array}{l}\text { Wang } \\
{[29]}\end{array}$ & NR & $44 / 43$ & $49 / 38$ & $52(35 \sim 69)$ & PX $1.38 \mathrm{~g}, \mathrm{tid}+\mathrm{DDP}+5-\mathrm{Fu}$ & $\mathrm{DDP}+5-\mathrm{Fu}$ & $21 \mathrm{~d} \times 2$ & (1) (4) \\
\hline Fan et al. & III IV & $47 / 46$ & $55 / 38$ & $52(32 \sim 69)$ & $\mathrm{PX} 1.25 \mathrm{~g}, \mathrm{bid}+\mathrm{DDP}+5-\mathrm{Fu}$ & $\mathrm{DDP}+5-\mathrm{Fu}$ & $21 \mathrm{~d} \times 1$ & (1) \\
\hline $\begin{array}{l}\text { Ning and } \\
\text { Hao [31] }\end{array}$ & $\mathrm{II} \sim \mathrm{IV}$ & $121 / 49$ & $126 / 44$ & $54.3 / 56.1$ & PX $1.68 \mathrm{~g}$, tid + mFAM & mFAM & $\geq 21 \mathrm{~d} \times 3$ & (1) \\
\hline $\begin{array}{l}\text { Chen } \\
\text { et al. [32] }\end{array}$ & III IV & $30 / 28$ & $43 / 15$ & $\begin{array}{l}51(32 \sim 69) / \\
50(29 \sim 68)\end{array}$ & PX $1.38 \mathrm{~g}$,tid + ECF & $\mathrm{ECF}$ & $21 \mathrm{~d} \times 2$ & (1) (3) (4) \\
\hline $\mathrm{Gu}[33]$ & IV & $50 / 50$ & $61 / 39$ & $\begin{array}{c}45.81 \pm 8.79 / \\
45.17 \pm 8.92\end{array}$ & PX $1.15 \mathrm{~g}$, tid + DCF & DCF & $21 \mathrm{~d} \times 4$ & (1) (4) \\
\hline $\begin{array}{l}\text { Zhang } \\
\text { et al. [34] }\end{array}$ & III IV & $46 / 46$ & $61 / 31$ & $\begin{array}{c}54.3 \pm 6.8 / \\
52.6 \pm 6.3\end{array}$ & XAP 3 g, bid + PF & $\mathrm{PF}$ & $28 \mathrm{~d} \times 2$ & (1) (2) (3) (4) \\
\hline $\begin{array}{l}\text { Huang } \\
\text { and Guo } \\
{[35]}\end{array}$ & NR & $36 / 36$ & $41 / 31$ & $61.42 \pm 11.20$ & $\begin{array}{c}\text { XAP } 2.4 \mathrm{~g}, \text { tid + FOLFOX } 4 / \\
\text { XELOX/EOF }\end{array}$ & $\begin{array}{l}\text { FOLFOX4/XELOX/ } \\
\text { EOF }\end{array}$ & NR & (3) (4) \\
\hline $\begin{array}{l}\text { Wang } \\
{[36]}\end{array}$ & NR & $150 / 150$ & $166 / 134$ & $\begin{array}{c}62.34 \pm 8.37 / \\
63.16 \pm 8.84\end{array}$ & XAP $1.8 \sim 2.4 \mathrm{~g}, \mathrm{tid}+\mathrm{SOX}$ & SOX & $21 \mathrm{~d} \times 4$ & (1) \\
\hline Li [37] & IV & $32 / 30$ & $37 / 25$ & $\begin{array}{c}62.2 \pm 3.4 / \\
63.6 \pm 3.2\end{array}$ & XAP + chemotherapy & Chemotherapy & NR & (1) (4) \\
\hline Shi [38] & NR & $53 / 53$ & $56 / 50$ & $56.28 \pm 4.82$ & $\begin{array}{c}\text { XAP } 2.04 \sim 2.55 \mathrm{~g}, \mathrm{tid}+\mathrm{EOF} / \\
\text { OLF }\end{array}$ & $\mathrm{EOF} / \mathrm{OLF}$ & NR & (3) (4) \\
\hline
\end{tabular}


TABLE 1: Continued.

\begin{tabular}{|c|c|c|c|c|c|c|c|c|}
\hline \multirow{2}{*}{ Study ID } & \multirow{2}{*}{$\begin{array}{l}\text { TNM } \\
\text { stages }\end{array}$} & \multirow{2}{*}{$\begin{array}{c}\text { Sample } \\
\text { size }(E / C)\end{array}$} & \multirow{2}{*}{$\begin{array}{l}\text { Sex, } \\
\mathrm{M} / \mathrm{F}\end{array}$} & \multirow{2}{*}{ Age $(\mathrm{E} / \mathrm{C})$} & \multicolumn{2}{|c|}{ Intervention } & \multirow{2}{*}{$\begin{array}{l}\text { Course } \\
(\mathrm{d} \times \mathrm{c})\end{array}$} & \multirow{2}{*}{ Outcomes } \\
\hline & & & & & $\mathrm{E}$ & $\mathrm{C}$ & & \\
\hline Liu [39] & III & $46 / 46$ & $57 / 35$ & $\begin{array}{c}57.2 \pm 4.1 / \\
56.1 \pm 3.5\end{array}$ & ZQFZ $15 \mathrm{~g}$, bid + FOLFOX4 & FOLFOX4 & $\geq 14 \mathrm{~d} \times 2$ & (1) (3) (4) \\
\hline Wei [40] & NR & $30 / 30$ & $34 / 26$ & $43 \sim 72 / 46 \sim 75$ & $\begin{array}{c}\text { ZQFZ 5g, bid + 5-Fu + L- } \\
\text { OHP + CF + MMC }\end{array}$ & $\begin{array}{c}5-\mathrm{Fu}+\mathrm{L}- \\
\mathrm{OHP}+\mathrm{CF}+\mathrm{MMC}\end{array}$ & $28 \mathrm{~d} \times 1$ & (2) \\
\hline Hu et al. & $\mathrm{II} \sim \mathrm{IV}$ & $40 / 40$ & $46 / 34$ & $\begin{array}{c}54.3 \pm 10.3 / \\
52.5 \pm 11.1\end{array}$ & ZQFZ 5g, tid + MLF & MLF & $28 \mathrm{~d} \times 1$ & (2) \\
\hline $\begin{array}{l}\mathrm{Li} \text { and } \\
\text { Zhang }\end{array}$ & IV & $26 / 26$ & $34 / 18$ & $65 \sim 73$ & ZQFZ 5g, bid + S-1 & S-1 & $42 \mathrm{~d} \times 2$ & (1) (3) (4) \\
\hline$[42]^{\circ}$ & & & & & & & & \\
\hline
\end{tabular}

E, experimental group; C, control group; M, male; F, female; NR, no reported; d, day; c, cycle; ATK, Antike capsule; BZ, Bazhen granule; SQSYW, Shenqi Shiyiwei granule; HCS, Cinobufacin capsule; PX, Pingxiao capsule; XAP, Xiao'aiping tablet; ZQFZ, Zhenqi Fuzheng granule; (1), objective response rate; (2), performance status; (3), leucopenia; (4), gastrointestinal reaction.

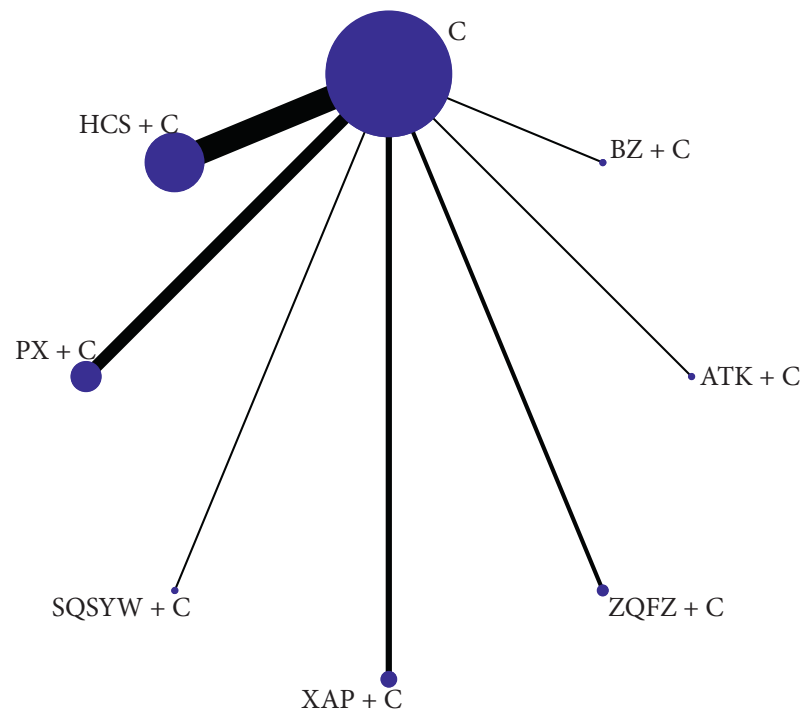

(a)

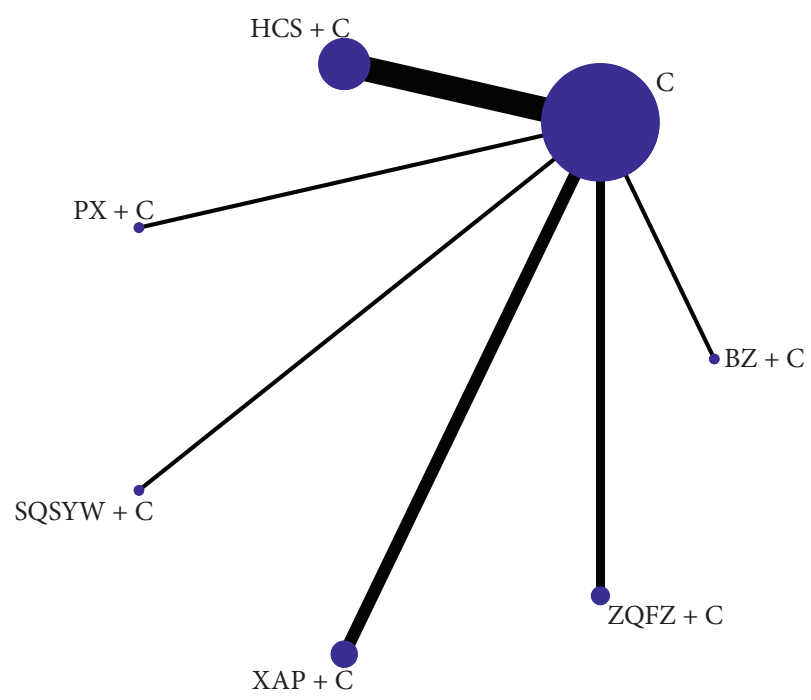

(c)

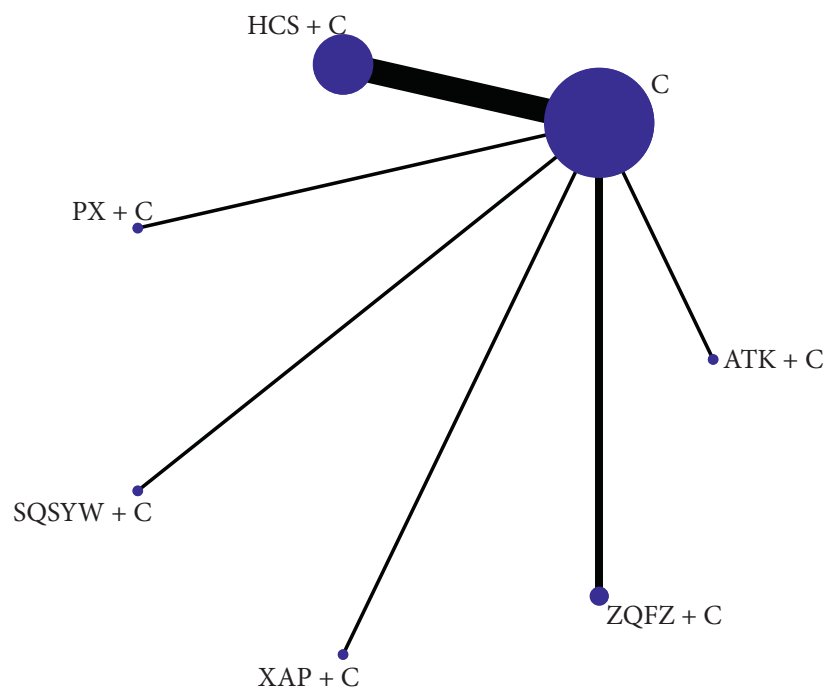

(b)

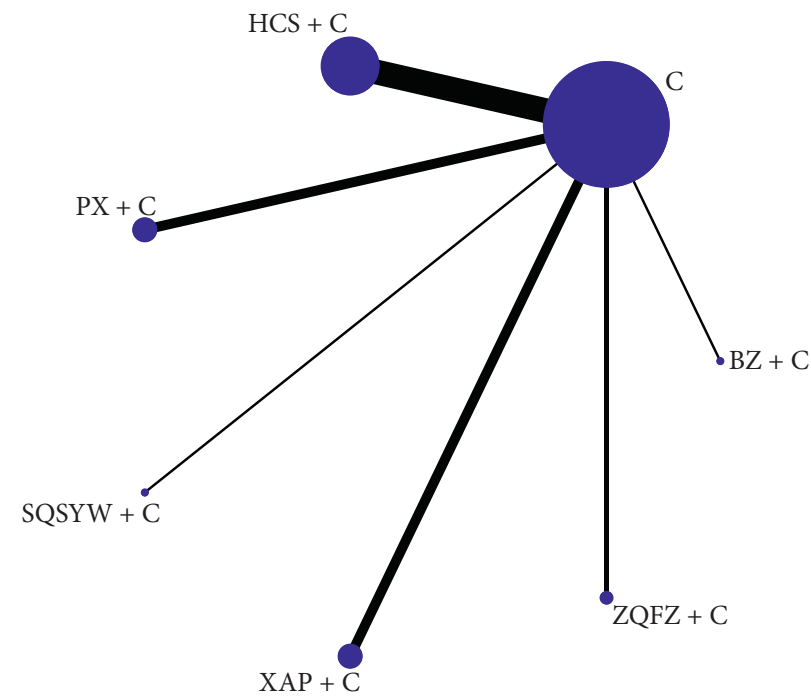

(d)

FIGURE 2: Network graph for 4 outcomes. (a) Objective response rate. (b) Performance status. (c) Leucopenia. (d) Gastrointestinal reaction. 


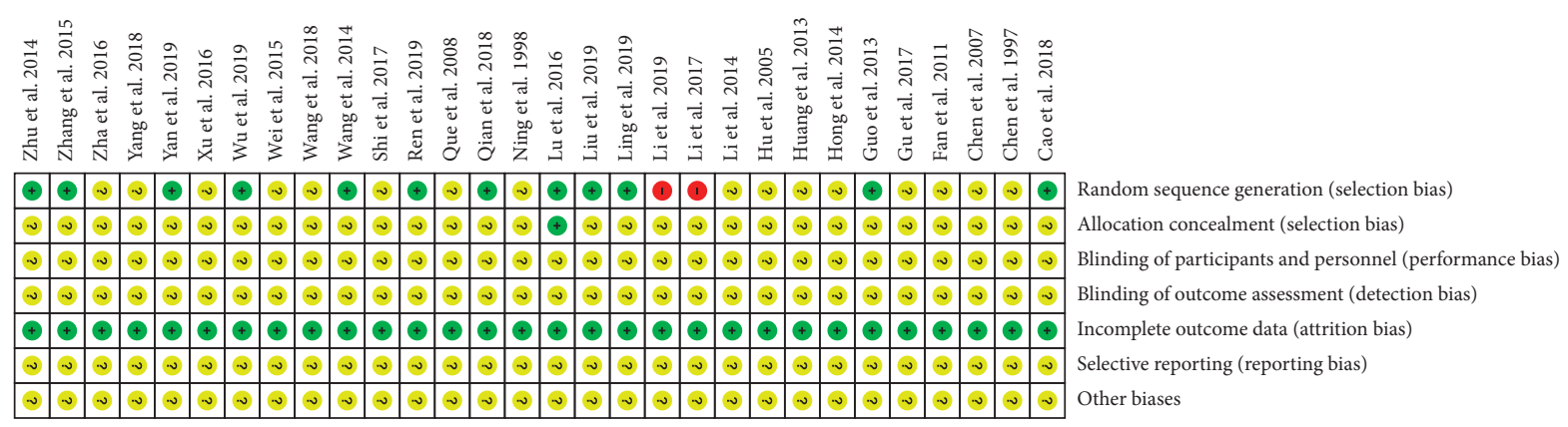

(a)

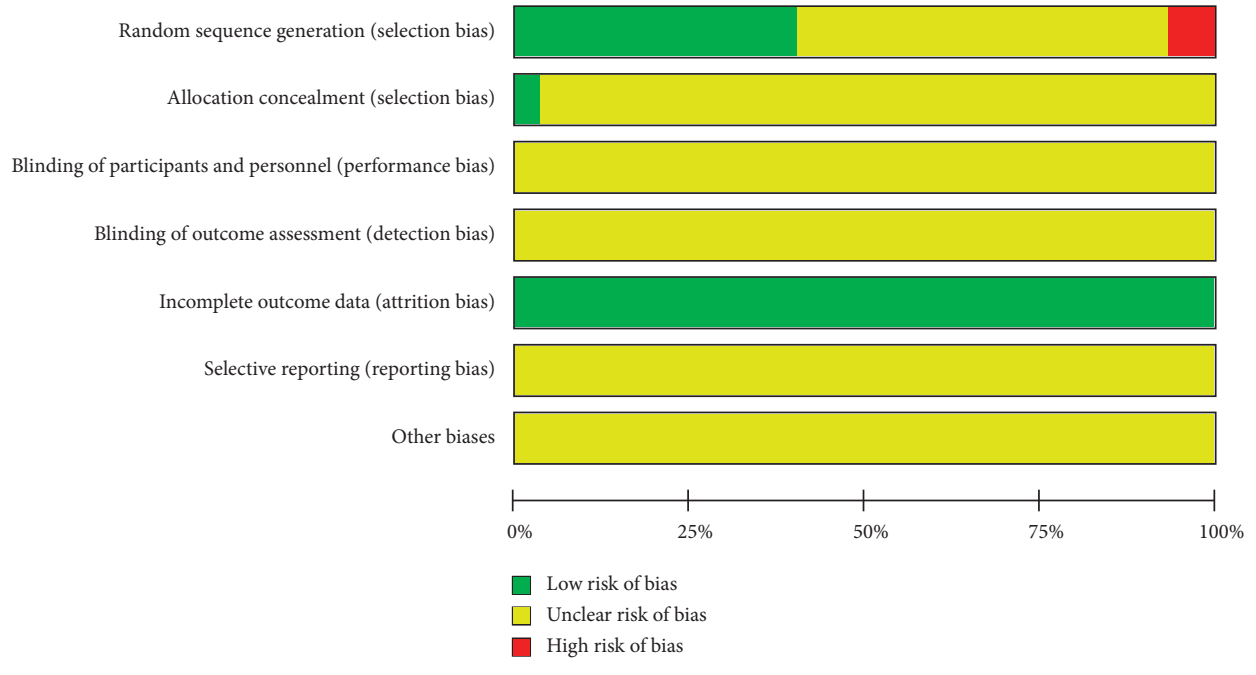

(b)

Figure 3: Risk of bias assessment.

subgroup, so the random effect model was used for analysis. The results of the meta-analysis showed that $\mathrm{BZ}+\mathrm{C}$, $\mathrm{HCS}+\mathrm{C}, \mathrm{XAP}+\mathrm{C}$, and $\mathrm{ZQFZ}+\mathrm{C}$ could significantly reduce the incidence of leucopenia compared with chemotherapy alone $(P<0.05)$, while SQSYW $+C$ and $P X+C$ had no significant difference compared with chemotherapy alone, as shown in Figure 6.

(2) Gastrointestinal Reaction. The results of the heterogeneity test showed that the heterogeneity of 22 studies was little $\left(P=0.666, I^{2}=0 \%\right)$, and the heterogeneity within each subgroup was also small. The results of the metaanalysis of the fixed-effect model showed that $\mathrm{BZ}+\mathrm{C}$, $\mathrm{HCS}+\mathrm{C}, \mathrm{XAP}+\mathrm{C}$, and $\mathrm{ZQFZ}+\mathrm{C}$ could significantly reduce the incidence of gastrointestinal reactions compared with chemotherapy alone $(P<0.05)$, but SQSYW $+\mathrm{C}$ and $\mathrm{PX}+\mathrm{C}$ had no significant difference compared with chemotherapy alone, as shown in Figure 7.

\subsection{Results of the Network Meta-Analysis}

3.4.1. Objective Response Rate. A total of 26 RCTs involving seven oral Chinese patent medicines reported ORR. The results of network meta-analysis showed that: compared with chemotherapy alone, $\mathrm{BZ}+\mathrm{C}(\mathrm{OR}=0.31,95 \% \mathrm{CI} 0.11$ to $0.87), \mathrm{HCS}+\mathrm{C}(\mathrm{OR}=2.78,95 \% \mathrm{CI} 1.97$ to 3.95$), \mathrm{PX}+\mathrm{C}$
$(\mathrm{OR}=1.69,95 \%$ CI 1.13 to 2.56$)$, and $\mathrm{XAP}+\mathrm{C}(\mathrm{OR}=2.20$, 95\% CI 1.37 to 3.77 ) can significantly improve the objective response rate and clinical efficacy. However, there were no significant differences between different oral Chinese patent medicines. The effect value of each intervention is shown in Table 2.

The rank probability of interventions is represented in Figure 8. For each intervention, the total rank probability was 1 . In terms of ORR, rank 1 was the best intervention, while rank $N$ was worst. The rank of oral Chinese patent medicines was BZ (1 RCT) $>$ HCS (12 RCTs) $>$ XAP (3 RCTs $)>$ ZQFZ (2 RCTs) $>$ PX (6 RCTs) $>$ ATK (1 RCT) $>$ SQSYW (1 RCT).

3.4.2. Performance Status. A total of 13 RCTs involving six oral Chinese patent medicines reported the improvement rate of the KPS score. There were significant differences between $\mathrm{HCS}+\mathrm{C}(\mathrm{OR}=0.33,95 \% \mathrm{CI} 0.21$ to 0.51$), \mathrm{PX}+\mathrm{C}(\mathrm{OR}=0.27$, $95 \% \mathrm{CI} 0.07$ to 0.91$), \mathrm{XAP}+\mathrm{C}(\mathrm{OR}=0.03,95 \% \mathrm{CI} 0.00$ to 0.12$)$, $\mathrm{ZQFZ}+\mathrm{C}(\mathrm{OR}=0.28,95 \% \mathrm{CI} 0.10$ to 0.77$)$ and chemotherapy alone. Besides, the performance status of the patients with gastric cancer improved by the combination of XAP and chemotherapy was significantly better than the other five oral Chinese patent medicines. There is no statistically significant difference between the other interventions, as shown in Table 2. 


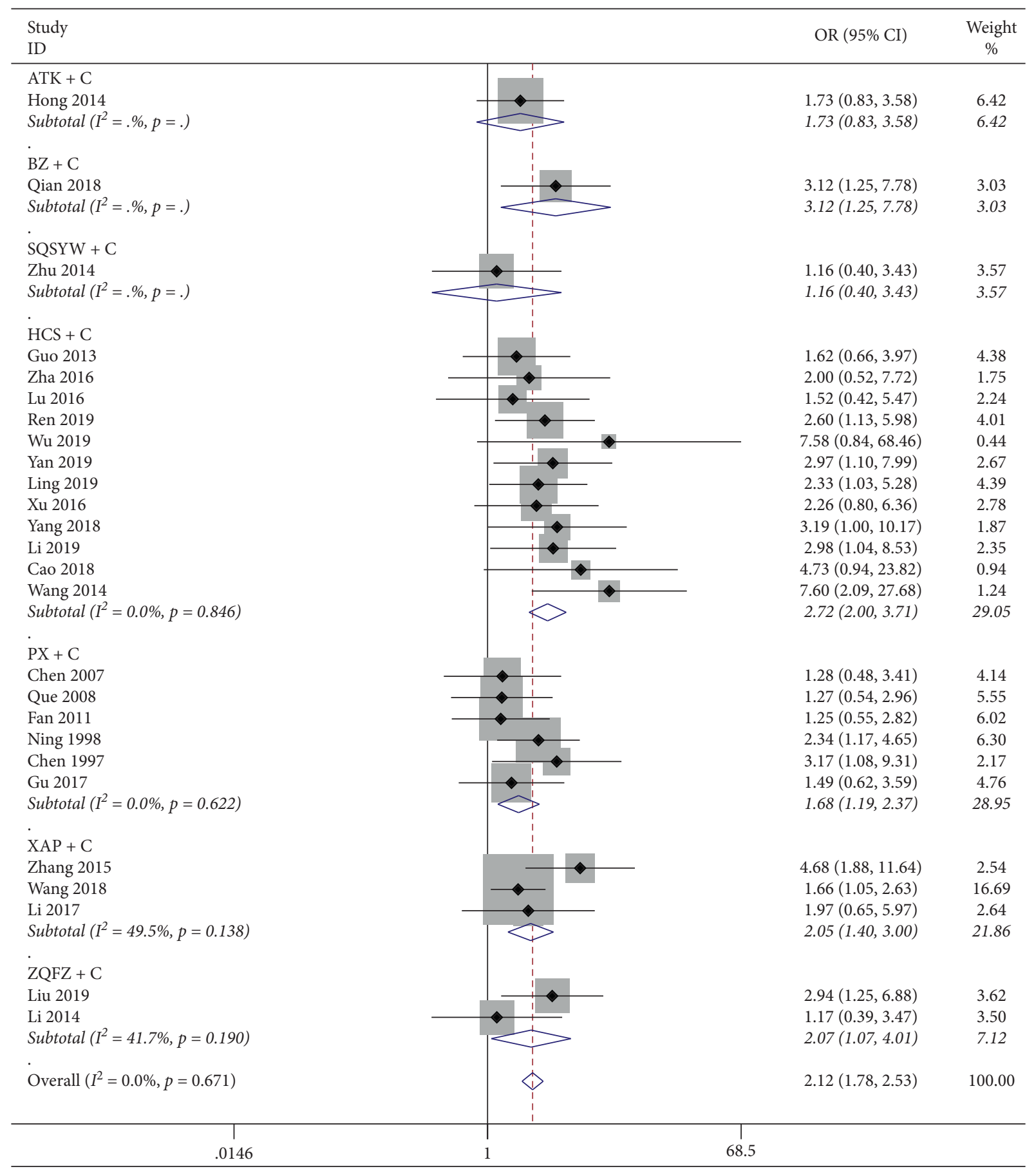

Figure 4: Meta-analysis results of the objective response rate.

The rank probability of each intervention is displayed in Figure 8. As same as ORR, rank 1 represented the best effect here. The rank of oral Chinese patent medicines was: XAP (1 RCT $)>$ PX $(1$ RCT $)>$ SQSYW (1 RCT) $>$ HCS (7 RCTs) $>$ ZQFZ (2 RCTs) > ATK (1 RCT).

3.4.3. ADRs. (1) Leucopenia. A total of 14 RCTs involving six oral Chinese patent medicines reported the incidence of leucopenia. The results showed that only the combination of HCS and chemotherapy (OR $=0.30,95 \%$ CI 0.13 to 0.65$)$ could significantly reduce the incidence of leucopenia compared with chemotherapy alone. There is no significant difference between the other interventions, as shown in Table 3.

The rank probability of each intervention was presented in Figure 9. In terms of leucopenia, a larger portion of rank 6 represented better effects, while rank 1 was the worst. The rank of oral Chinese patent medicines was ZQFZ (2 RCTs) $>$ BZ $(1$ RCT $)>$ HXS (6 RCTs) $>$ SQSYW $(1$ RCT $)>$ PX $(1$ RCT) $>$ XAP (3 RCTs). 


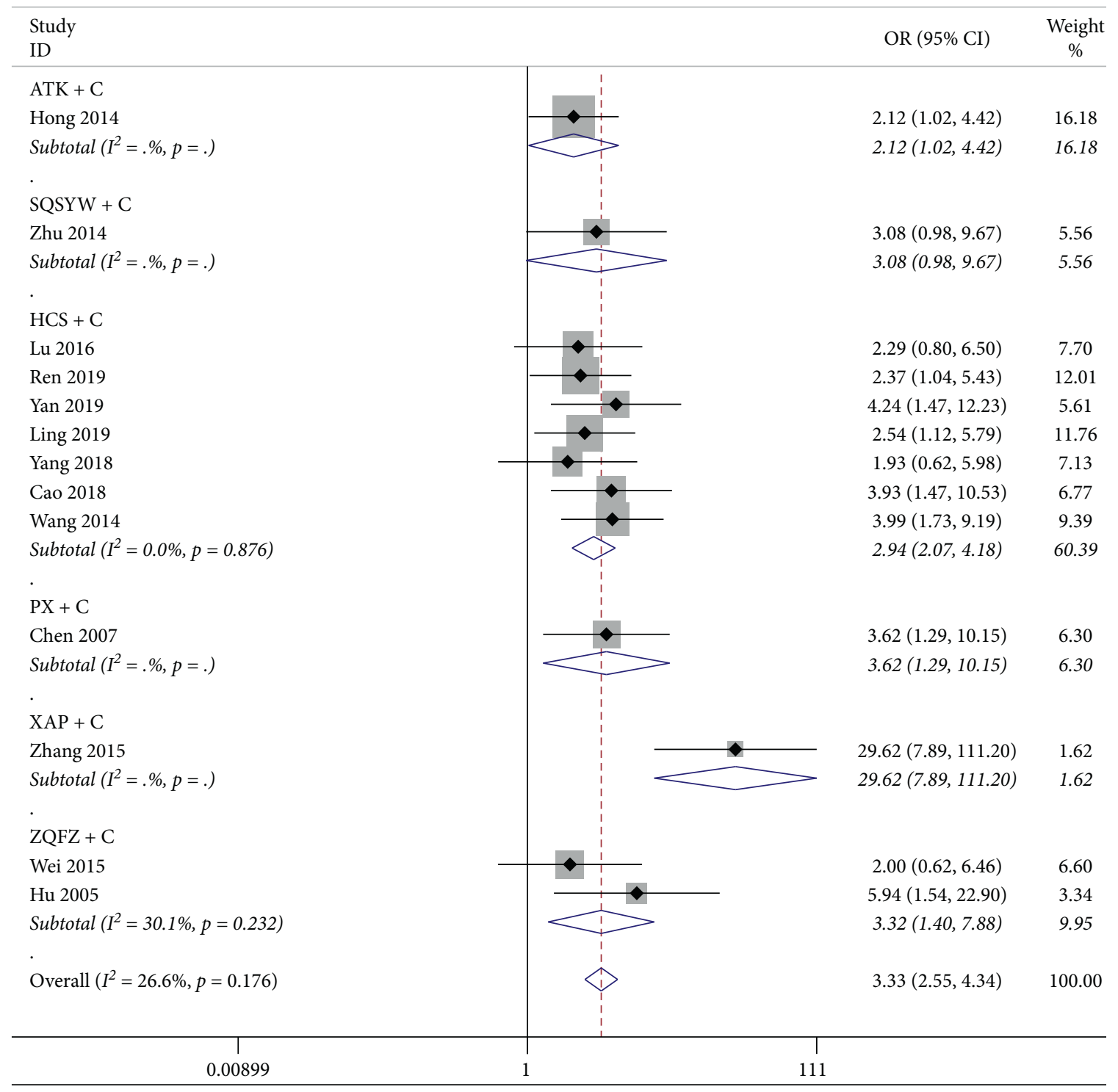

FIGURE 5: Meta-analysis results of performance status.

(2) Gastrointestinal Reaction. A total of 22 RCTs involving six oral Chinese patent medicines provided the data of gastrointestinal response. The results showed that $\mathrm{BZ}+\mathrm{C}$ $(\mathrm{OR}=0.26,95 \% \mathrm{CI} 0.07$ to 0.83$), \mathrm{XAP}+\mathrm{C}(\mathrm{OR}=2.95,95 \%$ CI 1.65 to 5.88$)$, and ZQFZ + C (OR $=2.92,95 \%$ CI 1.24 to 7.06) can significantly reduce the incidence of gastrointestinal response compared with chemotherapy alone. There is no significant difference between the other interventions, as shown in Table 3.

The rank probability of each intervention was displayed in Figure 9. Like leucopenia, rank 6 was the best. The rank of oral Chinese patent medicines was BZ (1 RCT) $>$ ZQFZ (1 RCT) $>$ XAP (4 RCTs) > SQSYW (1 RCT) > PX (4 RCTs) $>$ HCS (10 RCTs).

3.5. Publication Bias. The publication bias of the RCTs was measured with a comparison-adjusted funnel plot. Funnel plots of most outcomes were not quite symmetric, indicating potential publication bias in the network (Figure 10).

\section{Discussion}

As a common malignant tumour, gastric cancer has a high incidence and recurrence rate, and its prevention and control have become an urgent public health issue. Traditional Chinese medicine has been extensively applied in China and has shown certain advantages in the treatment of gastric cancer. At present, relevant studies in China have used network meta-analysis to evaluate the efficacy and safety of Chinese herbal injections combined with chemotherapy in the treatment of gastric cancer, respectively, from the aspects of short-term efficacy, quality of life, the incidence of adverse reactions, and so on, to help clinicians choose the best scheme in different interventions [43-46]. However, the network meta-analysis of traditional Chinese 


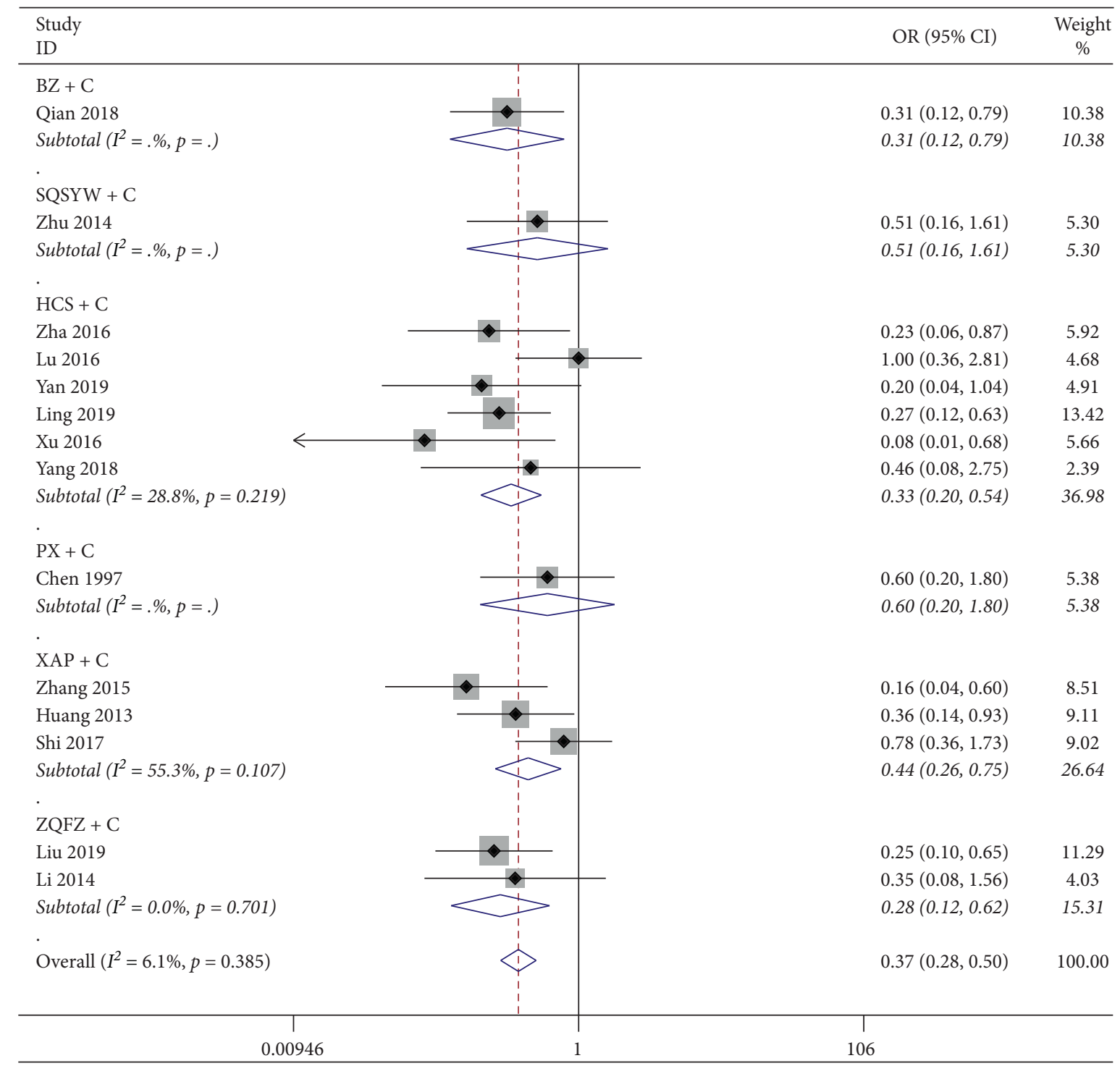

Figure 6: Meta-analysis results of leucopenia.

medicine combined with chemotherapy in the treatment of gastric cancer is mostly aimed at Chinese herbal injections, and the direction of oral Chinese patent medicine combined with chemotherapy has not been involved. The medicines listed in this study are commonly used oral Chinese patent medicines for gastric cancer recommended in the Clinical Practice Guidelines of Chinese Medicine in Oncology, and these medicines are included in the National Basic Medical Insurance Drugs List of China. According to the eligibility criteria, this NMA identified 30 RCTs involving seven oral Chinese patent medicines, namely, HCS, PX, XAP, ZQFZ, BZ, ATK, and SQSYW. In this study, the efficacy and safety of 7 kinds of oral Chinese patent medicine combined with chemotherapy in the treatment of gastric cancer were compared. The results of the network meta-analysis showed the following. (1) In terms of improving the objective response rate, compared with chemotherapy alone, $\mathrm{BZ}+\mathrm{C}$ $(\mathrm{OR}=0.31,95 \% \mathrm{CI} 0.11$ to 0.87$), \mathrm{HCS}+\mathrm{C}(\mathrm{OR}=2.78,95 \%$ CI 1.97 to 3.95$), \mathrm{PX}+\mathrm{C}(\mathrm{OR}=1.69,95 \% \mathrm{CI} 1.13$ to 2.56$)$, and
$\mathrm{XAP}+\mathrm{C}(\mathrm{OR}=2.20,95 \% \mathrm{CI} 1.37$ to 3.77$)$ can significantly improve the objective response rate and clinical efficacy. However, there was no significant difference between different oral Chinese patent medicines. The results of probability ranking show that the top three are $\mathrm{BZ}+\mathrm{C}, \mathrm{HCS}+\mathrm{C}$, and XAP $+\mathrm{C}$, respectively. (2) In terms of improving performance status, there were significant differences between $\mathrm{HCS}+\mathrm{C} \quad(\mathrm{OR}=0.33, \quad 95 \% \quad \mathrm{CI} \quad 0.21$ to 0.51$), \quad \mathrm{PX}+\mathrm{C}$ $(\mathrm{OR}=0.27,95 \% \mathrm{CI} 0.07$ to 0.91$), \mathrm{XAP}+\mathrm{C}(\mathrm{OR}=0.03,95 \%$ CI 0.00 to 0.12$), \mathrm{ZQFZ}+\mathrm{C}(\mathrm{OR}=0.28,95 \% \mathrm{CI} 0.10$ to 0.77$)$, and chemotherapy alone. The pair-pair comparison of oral Chinese patent medicine showed that XAP $+\mathrm{C}$ improved the quality of life of gastric cancer patients significantly better than $\mathrm{ATK}+\mathrm{C}, \mathrm{HCS}+\mathrm{C}, \mathrm{PX}+\mathrm{C}, \mathrm{SQSYW}+\mathrm{C}$, and $\mathrm{ZQFZ}+\mathrm{C}$. In contrast, other pair-pair comparison showed no statistical significance. The probability ranking results show that the top three are $\mathrm{XAP}+\mathrm{C}, \mathrm{PX}+\mathrm{C}$, and SQSYW + C, respectively. (3) In terms of reducing toxic and side effects, $\mathrm{HCS}+\mathrm{C}(\mathrm{OR}=0.30,95 \% \mathrm{CI} 0.13$ to 0.65$)$ can 


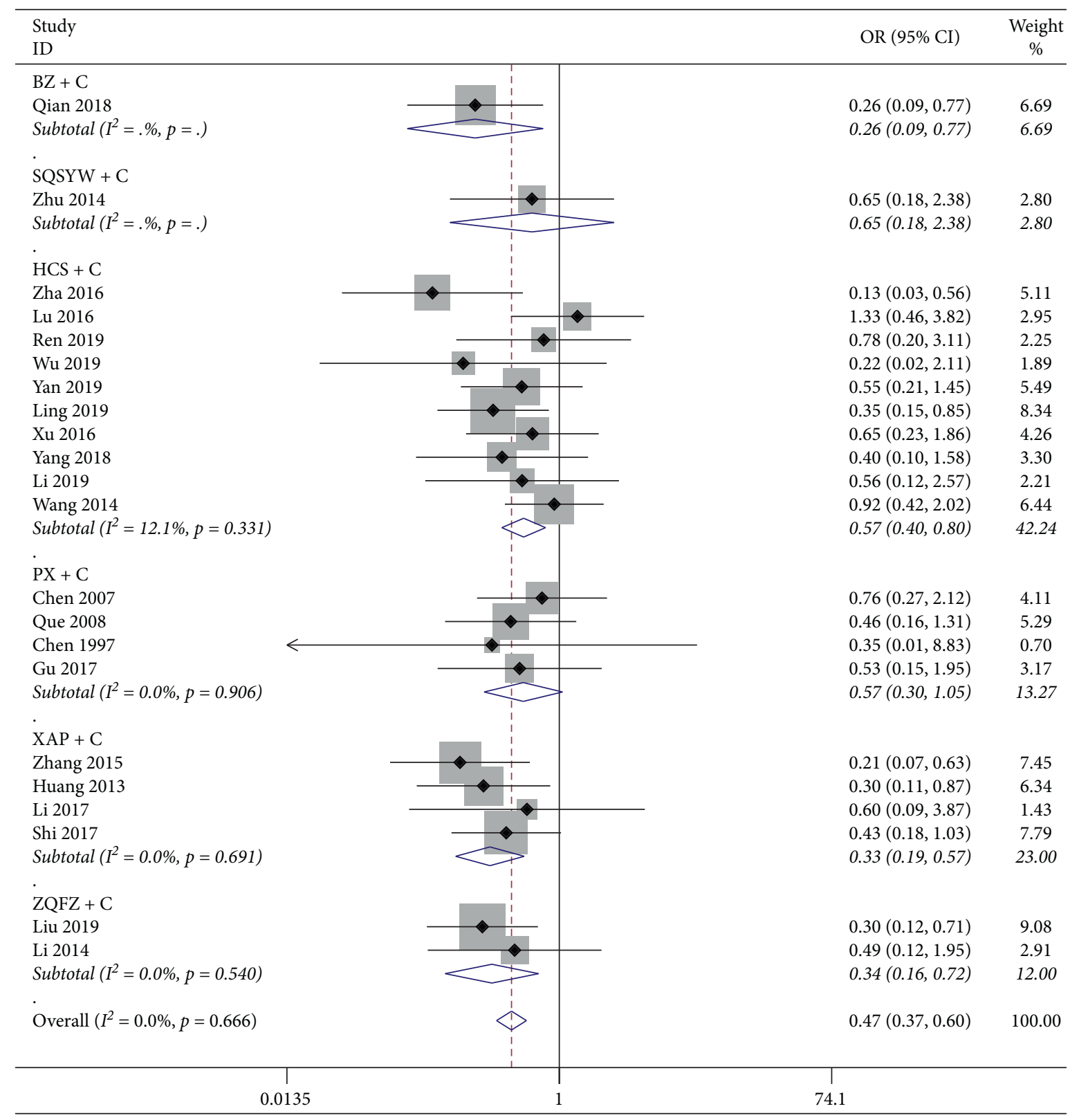

Figure 7: Meta-analysis results of gastrointestinal reaction.

TABLE 2: Network meta-analysis results of objective response rate (upper right quarter) and performance status (lower left quarter).

\begin{tabular}{|c|c|c|c|c|c|c|c|}
\hline $\mathrm{ATK}+\mathrm{C}$ & $\begin{array}{c}1.87(0.47 \\
7.30)\end{array}$ & $\begin{array}{c}0.58(0.24 \\
1.39)\end{array}$ & $\begin{array}{c}1.60(0.62, \\
4.21)\end{array}$ & $0.99(0.36,2.55)$ & $0.69(0.14,3.18)$ & $1.27(0.47,3.58)$ & $\begin{array}{c}1.19(0.37, \\
3.79)\end{array}$ \\
\hline- & $\mathrm{BZ}+\mathrm{C}$ & $0.31(0.11,0.87)$ & $\begin{array}{c}0.86(0.29 \\
2.60)\end{array}$ & $0.53(0.17,1.59)$ & $0.38(0.07,1.77)$ & $0.69(0.22,2.20)$ & $\begin{array}{c}0.63 \\
(0.16,2.27)\end{array}$ \\
\hline $2.13(0.76,6.30)$ & - & C & $\begin{array}{c}2.78(1.97 \\
3.95)\end{array}$ & $1.69(1.13,2.56)$ & $1.20(0.33,4.10)$ & $2.20(1.37,3.77)$ & $\begin{array}{c}2.04(0.97 \\
4.33)\end{array}$ \\
\hline $0.71(0.23,2.33)$ & - & $0.33(0.21,0.51)$ & $\mathrm{HCS}+\mathrm{C}$ & $0.61(0.35,1.04)$ & $0.43(0.12,1.53)$ & $0.79(0.44,1.48)$ & $\begin{array}{c}0.73(0.33 \\
1.67)\end{array}$ \\
\hline $0.59(0.11,2.85)$ & - & $\begin{array}{c}0.27(0.07 \\
0.91)\end{array}$ & $\begin{array}{c}0.81(0.19 \\
3.01)\end{array}$ & $\mathbf{P X}+\mathbf{C}$ & $0.70(0.19,2.58)$ & $1.30(0.70,2.57)$ & $\begin{array}{c}1.21(0.50, \\
2.85)\end{array}$ \\
\hline $0.65(0.12,3.91)$ & - & $0.31(0.08,1.16)$ & $\begin{array}{l}0.91(0.22 \\
\quad 3.71)\end{array}$ & $1.14(0.18,7.65)$ & SQSYW + C & $1.83(0.49,7.51)$ & $\begin{array}{c}1.71(0.38, \\
7.20)\end{array}$ \\
\hline $0.06(0.01,0.39)$ & - & $\begin{array}{c}0.03(0.00 \\
0.12)\end{array}$ & $\begin{array}{c}0.09(0.01 \\
0.40)\end{array}$ & $0.11(0.01,0.80)$ & $0.09(0.01,0.73)$ & $\mathrm{XAP}+\mathrm{C}$ & $\begin{array}{c}0.92(0.37 \\
2.25)\end{array}$ \\
\hline $0.62(0.14,2.59)$ & - & $\begin{array}{c}0.28(0.10 \\
0.77)\end{array}$ & $\begin{array}{l}0.84(0.28 \\
2.61)\end{array}$ & $1.09(0.22,5.76)$ & $0.97(0.16,5.09)$ & $\begin{array}{c}10.12 \\
(1.59,85.37)\end{array}$ & $\mathrm{ZQFZ}+\mathrm{C}$ \\
\hline
\end{tabular}

The values in italics indicate there is a significant difference between the two groups. 


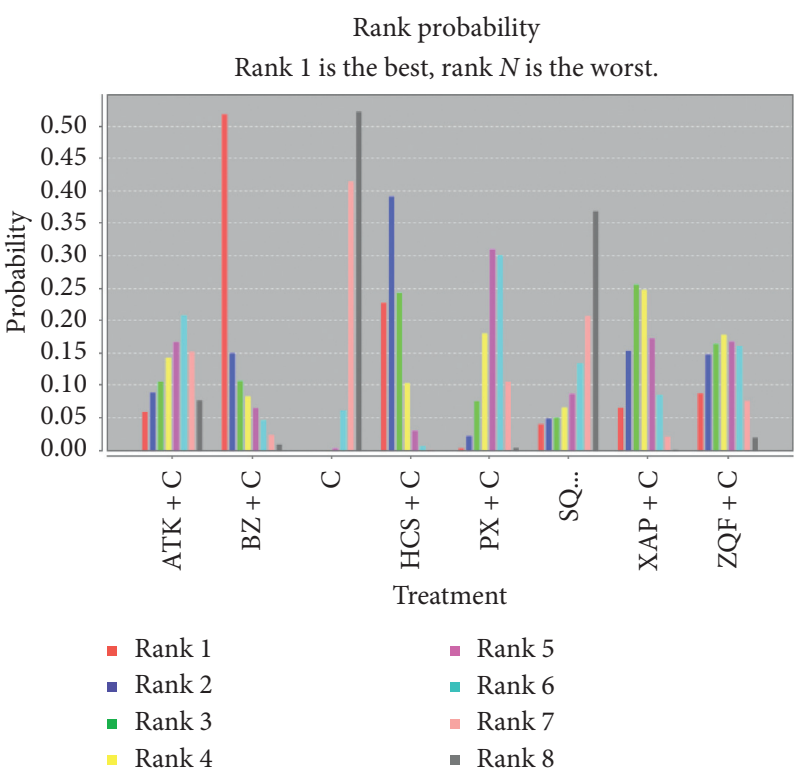

(a)

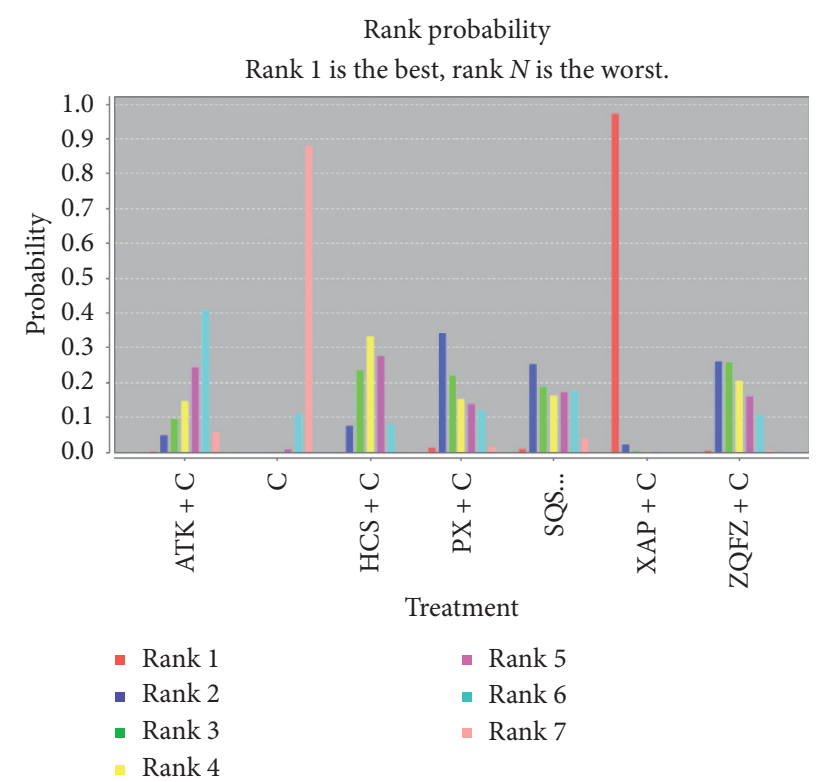

(b)

FIgURE 8: The ranking probability of each intervention. Note. (a) Objective response rate. (b) Performance status.

TABLE 3: Results of the network meta-analysis for leucopenia (upper right quarter) and gastrointestinal reaction (lower left quarter).

\begin{tabular}{lcccccc}
\hline $\mathrm{BZ}+\mathrm{C}$ & $3.24(0.57,19.51)$ & $0.96(0.14,6.41)$ & $1.93(0.15,23.60)$ & $1.53(0.12,20.54)$ & $1.28(0.16,9.39)$ & $0.88(0.10,8.09)$ \\
\hline $0.26(0.07,0.83)$ & $\mathrm{C}$ & $0.30(0.13,0.65)$ & $0.60(0.09,3.59)$ & $0.48(0.07,3.12)$ & $0.40(0.13,1.05)$ & $0.27(0.07,1.04)$ \\
$0.46(0.12,1.68)$ & $1.79(1.17,2.84)$ & HCS + C & $2.01(0.26,15.23)$ & $1.62(0.23,13.25)$ & $1.35(0.36,4.86)$ & $0.91(0.20,4.58)$ \\
$0.47(0.11,1.84)$ & $1.85(0.94,3.90)$ & $1.03(0.44,2.41)$ & $\mathbf{P X}+\mathbf{C}$ & $0.81(0.06,11.46)$ & $0.67(0.08,5.54)$ & $0.46(0.05,4.65)$ \\
$0.40(0.05,2.67)$ & $1.52(0.36,6.58)$ & $0.85(0.18,3.81)$ & $0.83(0.17,4.26)$ & SQSYW + C & $0.83(0.09,6.08)$ & $0.56(0.06,5.76)$ \\
$0.73(0.18,3.04)$ & $2.95(1.65,5.88)$ & $1.65(0.78,3.58)$ & $1.62(0.62,4.28)$ & $1.99(0.39,9.86)$ & XAP + C & $0.67(0.14,4.16)$ \\
$0.74(0.15,3.08)$ & $2.92(1.24,7.06)$ & $1.61(0.59,4.34)$ & $1.55(0.49,4.87)$ & $1.88(0.33,11.05)$ & $1.01(0.32,2.87)$ & ZQFZ+C \\
\hline
\end{tabular}

Rank probability

Rank 1 is the worst, $\operatorname{rank} N$ is the best.

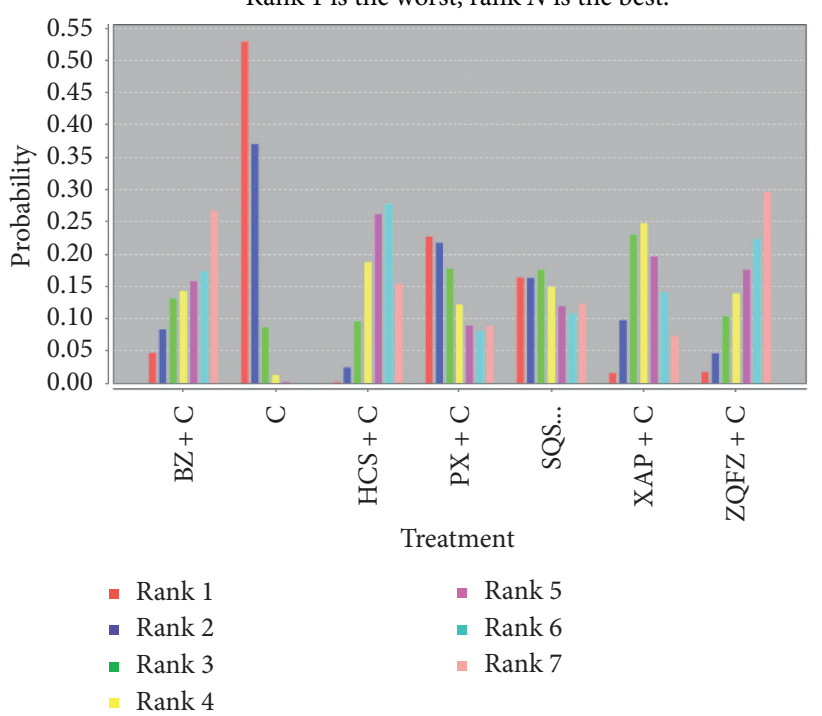

(a)

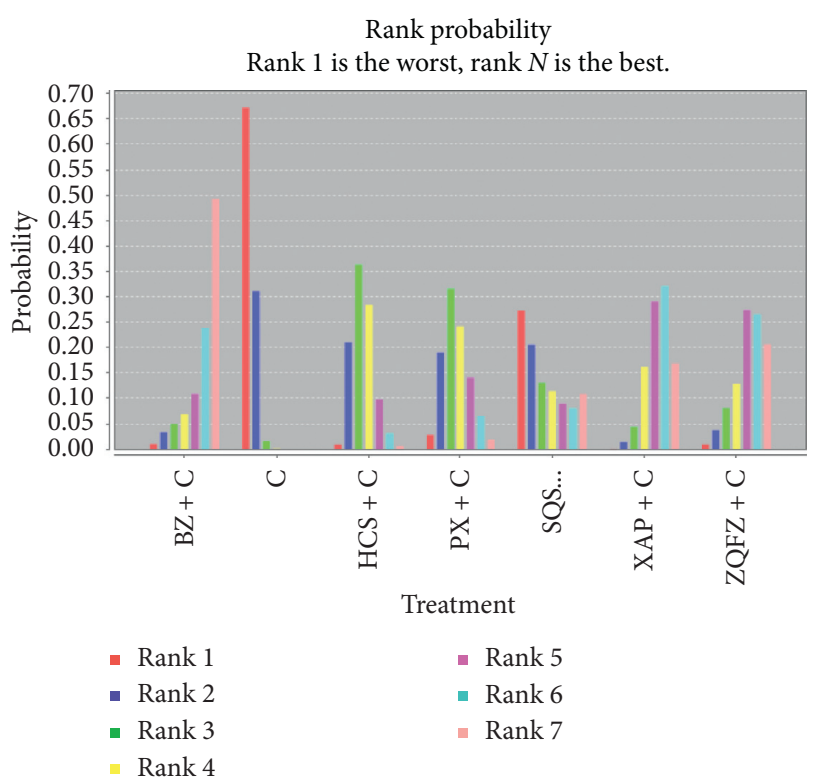

(b)

FIGURE 9: The rank probability of each intervention. (a) Leucopenia. (b) Gastrointestinal reaction. 


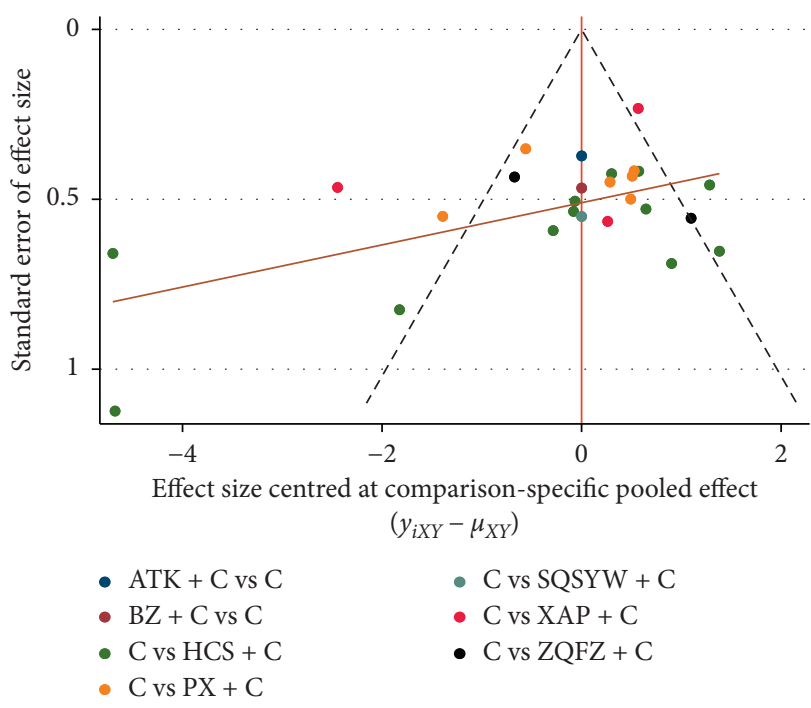

(a)

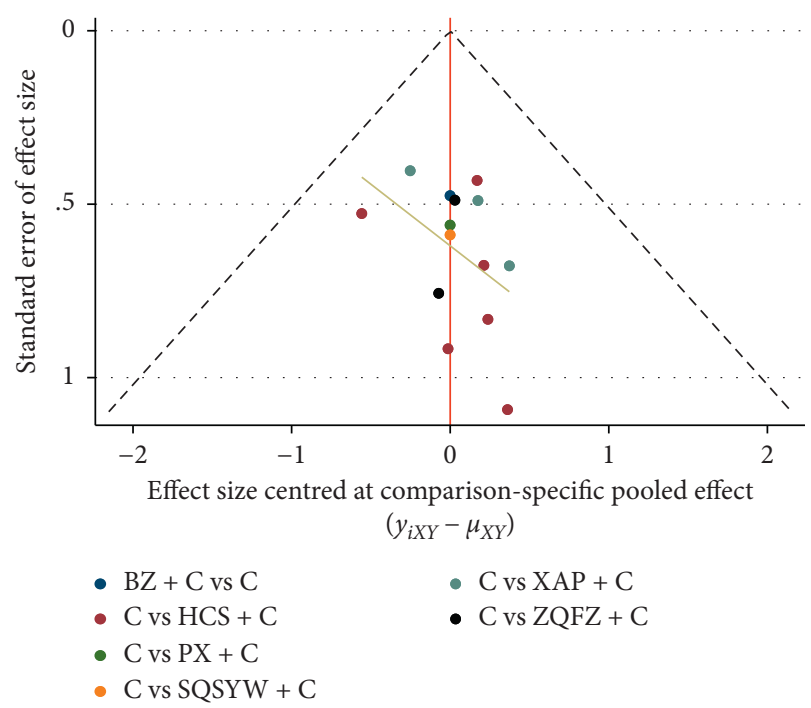

(c)

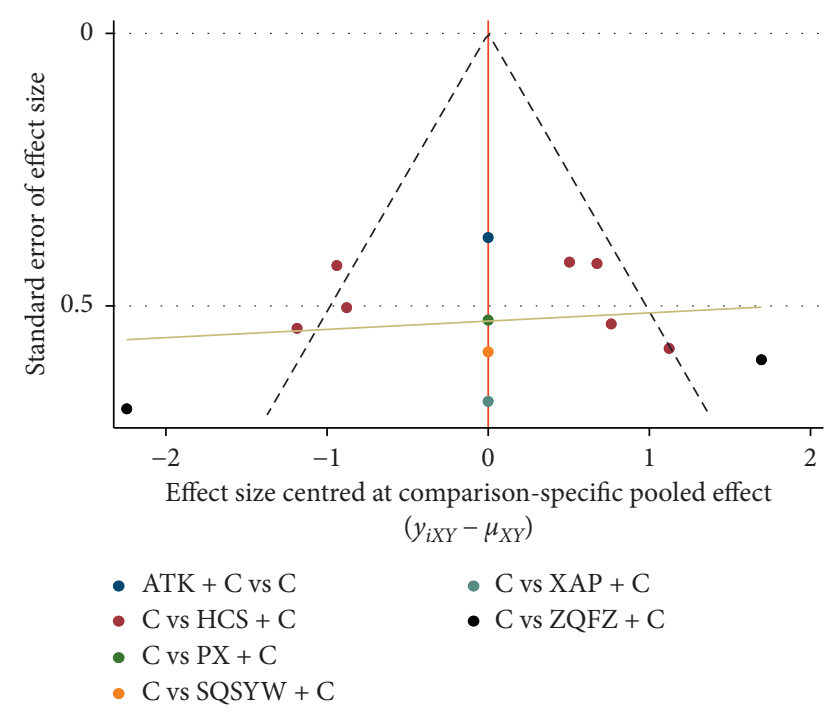

(b)

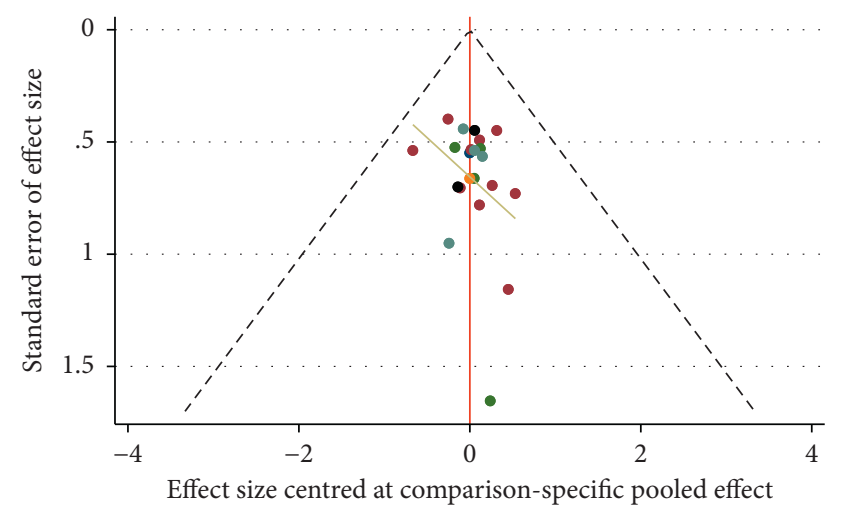

$\left(y_{i X Y}-\mu_{X Y}\right)$

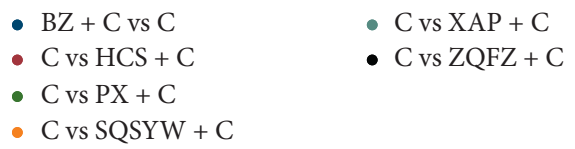

(d)

FIGURe 10: Funnel plot for 4 outcomes. (a) Objective response rate. (b) Performance status. (c) Leucopenia. (d) Gastrointestinal reaction.

significantly reduce the incidence of leucopenia, and there was no significant difference between the other two interventions. The probability ranking results show that the top three are $\mathrm{ZQFZ}+\mathrm{C}, \mathrm{BZ}+\mathrm{C}$, and $\mathrm{HCS}+\mathrm{C}$, respectively; $\mathrm{BZ}+\mathrm{C} \quad(\mathrm{OR}=0.26, \quad 95 \% \quad \mathrm{CI} \quad 0.07$ to 0.83$), \mathrm{XAP}+\mathrm{C}$ $(\mathrm{OR}=2.95,95 \% \mathrm{CI} 1.65$ to 5.88$)$, and $\mathrm{ZQFZ}+\mathrm{C}(\mathrm{OR}=2.92$, $95 \%$ CI 1.24 to 7.06 ) can significantly reduce the incidence of gastrointestinal reactions. There was no significant difference between the other two interventions. The probability ranking results show that the top three are $\mathrm{BZ}+\mathrm{C}$, $\mathrm{ZQFZ}+\mathrm{C}$, and XAP $+\mathrm{C}$, respectively.

The results of this study suggest that Bazhen granule combined with chemotherapy in the treatment of gastric cancer may be the best way to improve the clinical efficacy and reduce the adverse reactions of chemotherapy compared with the other six kinds of Chinese patent medicine. However, Bazhen granule is limited by the number and sample size of the included study, and its statistical test efficacy is low. Therefore, based on the current evidence, we suggest that clinicians should make the best choice according to different therapeutic purposes when using oral Chinese patent medicine combined with chemotherapy to treat gastric cancer. When the purpose is to improve the chemotherapy efficiency of gastric cancer patients, it is recommended to choose Cinobufacin capsule first; when the purpose is to improve the performance status of patients, it is recommended to select Xiao'aiping tablet first; when the purpose is to reduce the side effects of chemotherapy, it is recommended to choose Bazhen granule or Zhenqi Fuzheng granule.

In recent years, a lot of achievements have been recorded in clinical and experimental research on the treatment of gastric cancer with traditional Chinese medicine. Cinobufacin is a Traditional Chinese medicine 
Bufo gargarizans or Bufo melanostictus Schneider skin aqueous preparation, and its main active ingredient is bufogenin. It has the pharmacological effects of antitumour and immune promotion [47]. Studies on its antitumour mechanism have shown that Cinobufacin can inhibit tumour cell proliferation, induce tumour cell apoptosis, inhibit tumour angiogenesis, enhance immune function, and so on [48]. Its related preparations are widely used in the treatment of gastric cancer and other malignant tumours and show good efficacy. Xiao'aiping tablet is a kind of oral Chinese patent medicine commonly used by gastric cancer patients. Its core component is Marsdenia Tenacissima Caulis, which has the effect of preventing tumour cells from mitosis and promoting tumour cells apoptosis [49]. Modern pharmacological research also showed that Xiao'aiping tablet could reduce the content of transforming growth factor- $\alpha$ (TGF- $\alpha$ ) and vascular endothelial growth factor (VEGF) in patients with gastric cancer, to inhibit the invasion, metastasis, and angiogenesis of gastric cancer cells [50]. Zhenqi Fuzheng granule is an oral preparation composed of Astragali Radix and Ligustri Lucidi Fructus. It has the effects of improving human immunity, supporting the normal and tonifying the deficiency, tonifying qi and nourishing yin, and improving leucopenia caused by radiotherapy and chemotherapy in cancer patients. Bazhen granule is a Chinese patent medicine composed of Paeoniae Radix Alba, Atractylodis Macrocephalae Rhizoma, Atractylodes Macrocephala, Chuanxiong Rhizoma, Angelicae Sinensis Radix, Poria, Glycyrrhizae Radix Et Rhizoma, and Rehmanniae Radix Preaparata, which has the effect of tonifying qi and blood. The research shows that Bazhen granules can regulate the imbalance of many trace elements in the body and improve the immune function of patients with malignant tumours, especially those with deficiency of qi and blood [51]. In general, different types of oral Chinese patent medicines have diverse effects and functions on gastric cancer patients. In the clinical application of such drugs, we should combine the experience of doctors, the situation of patients, and a high level of evidence-based medicine research to choose.

This study takes the initiative to compare the efficacy and safety of a variety of oral Chinese patent medicines in the treatment of gastric cancer. However, the limitations of this study should not be ignored: (1) the included studies are all Chinese literature, and there may be language bias; (2) the quality of the included studies is general, most of the random methods are not explicitly explained, and most of the studies do not provide information about the distribution concealment and blind method, which may affect the reliability of the results; (3) funnel plot results suggest that there is a higher possibility of publication bias, which may affect the authenticity of the results; (4) there is a lack of direct comparative study between different oral Chinese patent medicines, and the confidence interval is wide, which may affect the statistical efficacy; (5) limited by the specific chemotherapy regimen, it failed to evaluate the effectiveness of the same oral Chinese patent medicine combined with different chemotherapy regimens; (6) limited by the included study, the selected outcome is the short-term efficacy index, and it failed to evaluate the longterm efficacy for gastric cancer; (7) the studies included in the analysis are all conducted in Chinese population. It is not clear whether our conclusions apply to other populations. Therefore, in the future, multicentre, large sample, and high-quality research can be organized to further clarify the effectiveness and safety of oral Chinese patent medicine in the treatment of gastric cancer and define its clinical feasibility, to achieve the initial purpose of guiding clinical practice.

\section{Conclusions}

In conclusion, oral Chinese patent medicine can play a useful role in enhancing the efficacy and reducing the toxicity of chemotherapy in gastric cancer patients. Among the seven drugs, Cinobufacin capsule and Xiao'aiping tablet are the best choices in improving the clinical efficacy, and Bazhen granule and Zhenqi Fuzheng granule are the best choices in reducing the adverse reactions of chemotherapy. Bazhen granule showed a good effect in this network meta-analysis. In the future, we should pay more attention to the effect of Bazhen granule combined with chemotherapy in the treatment of gastric cancer. Given the limitations of this study, the application of the conclusions of this study should be carefully selected.

\section{Abbreviations}

95\% CI: 95\% confidence interval

OR: Odds ratio

ADRs: Adverse drug reactions

NMA: Network meta-analysis

RCTs: Randomized controlled trials

IF: Inconsistency factor

CR: $\quad$ Complete response

PR: Partial response

ORR: Objective response rate

KPS: Karnofsky

ECOG: Eastern Cooperative Oncology Group

C: $\quad$ Chemotherapy

ATK: Antike capsule

BZ: Bazhen granule

SQSYW: Shenqi Shiyiwei granule

HCS: Cinobufacin capsule

PX: $\quad$ Pingxiao capsule

XAP: Xiao'aiping tablet

ZQFZ: Zhenqi Fuzheng granule.

\section{Data Availability}

The data used to support the findings of this study are included within the supplementary information files.

\section{Conflicts of Interest}

The authors declare no conflicts of interest in any aspects. 


\section{Acknowledgments}

This study was financially supported by the National Natural Science Foundation of China (no. 81673918); Pilot Gastric Cancer Project of Clinical Cooperation of Traditional Chinese and Western Medicine for Major and Difficult Diseases; and the Project of evidence-based capacity building of traditional Chinese medicine, Chinese Academy of Traditional Chinese Medicine, State Administration of Traditional Chinese Medicine (no. 2019XZZX-ZL003).

\section{Supplementary Materials}

Table S1: PRISMA NMA Checklist. Table S2: details of the search strategy for PubMed. (Supplementary Materials)

\section{References}

[1] F. Bray, J. Ferlay, I. Soerjomataram, R. L. Siegel, L. A. Torre, and A. Jemal, "Global cancer statistics 2018: GLOBOCAN estimates of incidence and mortality worldwide for 36 cancers in 185 countries," CA: A Cancer Journal for Clinicians, vol. 68, no. 6, pp. 394-424, 2018.

[2] C. Wanqing, S. Kexin, Z. Rongshou et al., "Cancer incidence and mortality in China, 2014," Chinese Journal of Cancer Research, vol. 30, no. 1, pp. 1-12, 2018.

[3] Z. Song, Y. Wu, J. Yang, D. Yang, and X. Fang, "Progress in the treatment of advanced gastric cancer," Tumour Biology the Journal of the International Society for Oncodevelopmental Biology \& Medicine, vol. 39, no. 7, Article ID 568834234, 2017.

[4] Z. Dong and J. Zhang, "Research progress in the treatment of gastric cancer with traditional Chinese medicine," Chinese Journal of Surgery of Integrated Traditional and Western Medicine, vol. 2, 2019.

[5] J. Liu, Q. Zhao, X. Qiao et al., "Research progress of Chinese traditional medicines for gastric cancer," Anti-Tumor Pharmacy, vol. 5, no. 6, pp. 16-19, 2015.

[6] G. Liu, L. Yu, H. Jia et al., "Progress of indirect comparison and network meta-analysis method research in systematic reviews," Chinese Journal of Evidence-Based Medicine, vol. 14, no. 10, pp. 1276-1280, 2014.

[7] B. Hutton, G. Salanti, D. M. Caldwell et al., "The PRISMA extension statement for reporting of systematic reviews incorporating network meta-analyses of health care interventions: checklist and explanations," Annals of Internal Medicine, vol. 162, no. 11, p. 777, 2015.

[8] H. Ling, Clinical Practice Guidelines of Chinese Medicine in Oncology, pp. 65-68, People's Medical Publishing House, Beijing, China, 2016.

[9] E. A. Eisenhauer, P. Therasse, J. Bogaerts et al., "New response evaluation criteria in solid tumours: revised RECIST guideline (version 1.1)," European Journal of Cancer, vol. 45, no. 2, p. 247, 2009.

[10] J. P. T. Higgins, D. G. Altman, P. C. Gotzsche et al., "The Cochrane Collaboration's tool for assessing risk of bias in randomised trials," BMJ, vol. 343, no. 18 2, p. d5928, 2011.

[11] D. Wang, J. Zhai, Z. Mou et al., "Discussing on the research of heterogeneity in meta-analysis," Chinese Journal of EvidenceBased Medicine, vol. 9, no. 10, pp. 1115-1118, 2009.

[12] X. Zeng, C. Zhang, and L. Du, "Using ADDIS software for implementation network meta-analysis," Chinese Journal of Evidence-Based Medicine, vol. 13, no. 12, pp. 117-124, 2013.
[13] W. Hong, L. Zhu, B. Liu et al., "Clinical study of Antike capsule combined with chemotherapy for advanced gastric cancer," Journal of New Chinese Medicine, vol. 46, no. 6, pp. 171-173, 2014.

[14] X. Qian and Y. Zuo, "Effects of Bazhen granule adjuvant chemotherapy on cellular immunity indexes and expression of P53 protein and IL-6 in advanced gastric cancer," Modern Medical Journal, vol. 46, no. 12, pp. 1339-1344, 2018.

[15] L. Zhu, Y. Yuan, and B. Bing, "Compound shenqishiyiweikeli combined with EOX chemotherapy in the treatment of 27 patients with advanced gastric carcinoma," Liaoning Journal of Traditional Chinese Medicine, vol. 41, no. 8, pp. 1693-1695, 2014.

[16] X. Guo, T. Sun, X. Wang et al., "Curative efficacy of cinobufacini adjuvant FOLFOX6 regimen in treatment of non operative elderly patients with advanced gastric cancer," Journal of Liaoning University of Traditional Chinese Medicine, vol. 15, no. 12, pp. 190-192, 2013.

[17] X. Zha and Z. Hang, "Effect of Cinobufacin capsule combined with oxaliplatin and tegafur in the treatment of advanced gastric cancer," Psychological Doctor, vol. 22, no. 18, pp. 126-127, 2016.

[18] B. Lu, J. Wu, R. Tong et al., "Clinical observation for the combination of Capecitabine and Cinobufacin capsule on treating elderly advanced gastric cancer," Journal of Liaoning University of Traditional Chinese Medicine, vol. 18, no. 9, pp. 84-87, 2016.

[19] L. Ren, "Clinical effect of Cinobufacin capsule combined with Sox regimens on 47 patients with advanced gastric cancer," Capital Food Medicine, vol. 26, no. 15, p. 80, 2019.

[20] X. Wu, Q. Wang, and H. Huang, "Efficacy of Cinobufagin capsule combined with xelox therapeutic regimen in treatment of advanced gastric cancer and its effect on patients' immunologic function," Evaluation and Analysis of Drug-Use in Hospitals of China, vol. 19, no. 2, pp. 195-196, 2019.

[21] L. Yan, C. Sheng, H. Su et al., "Study on the effect of cinobufagin capsule combined with oxaliplatin + capecitabine on immune function in patients with advanced gastric cancer and evaluation of efficacy," The Practical Journal of Cancer, vol. 34, no. 5, pp. 821-824, 2019.

[22] Z. Ling, "Effect of Cinobufacin capsule combined with chemotherapy on patients with advanced gastric cancer," Clinical Research, vol. 27, no. 9, pp. 140-141, 2019.

[23] Y. Xu and S. Liu, "Efficacy observation of Huachansu capsule combined with chemotherapy in treating advanced gastric cancer," World Chinese Medicine, vol. 11, no. 7, pp. 1212-1214, 2016.

[24] F. Yang and T. Zhang, "Clinical study of Cinobufacin capsule combined with chemotherapy in the treatment of advanced gastric cancer," Chinese Remedies \& Clinics, vol. 18, no. 2, pp. 266-268, 2018.

[25] A. Li, H. Yin, M. Lin et al., "Clinical study on Huachansu Tablets combined with SOX regimen in the treatment of advanced gastric cancer," Drugs \& Clinic, vol. 34, no. 3, pp. 714-718, 2019.

[26] P. Cao, "Effect of Cinobufacin tablets combined with tegafur on quality of life in patients with gastric cancer," Journal of Frontiers of Medicine, vol. 8, no. 20, pp. 124-125, 2018.

[27] F. Wang, L. Wu, X. Yue et al., "Clinical effect of gimeracil and oteracil porassium capsules combined with Hua Chan vegetarian capsules in the treatment of patients with gastric cancer," Chinese Journal of Clinical Oncology and Rehabilitation, vol. 21, no. 12, pp. 1485-1488, 2014. 
[28] J. Chen, Z. Li, C. Yang et al., "Clinical observation of Pingxiao capsule combined with chemotherapy in the treatment of 66 cases of gastric cancer," Journal of Modern Oncology, vol. 15, no. 1, pp. 65-66, 2007.

[29] J. Que and Z. Wang, "Clinical observation of Pingxiao capsule plus chemotherapy for the treatment of gastric cardia carcinoma," Journal of Modern Oncology, vol. 11, pp. 1927-1928, 2008.

[30] Z. Fan, X. Wang, Q. He et al., "Pingxiao capsule combined with chemotherapy in the treatment of 47 cases of advanced gastric cancer," Shaanxi Journal of Traditional Chinese Medicine, vol. 32, no. 1, pp. 6-7, 2011.

[31] T. Ning and Q. Hao, "Pingxiao capsule combined with chemotherapy in the treatment of 121 cases of advanced gastric cancer," Chinese Journal of Integrated Traditional and Western Medicine, vol. 18, no. 6, pp. 370-371, 1998.

[32] N. Chen, Y. Jin, and Y. Lai, "Clinical observation of Pingxiao capsule combined with chemotherapy for advanced gastric cancer," Strait Pharmaceutical Journal, vol. 9, no. 1, pp. 66-67, 1997.

[33] J. Gu, "Effect of Pingxiao capsule on advanced gastric cancer patients undergoing chemotherapy," Henan Medical Research, vol. 26, no. 8, pp. 1418-1419, 2017.

[34] H. Zhang, Z. Song, B. Li et al., "Attenuated intervention of Xiao'aiping capsules in PF regimen chemotherapy for gastric cancer patients," Chinese Journal of Biochemical and Pharmaceuticals, vol. 35, no. 2, pp. 140-142, 2015.

[35] J. Huang and Y. Guo, "Inhibitory effect of Xiao'aiping tablet on acute adverse reactions of patients with gastric cancer during chemotherapy," Journal of Emergency in Traditional Chinese Medicine, vol. 22, no. 2, p. 320, 2013.

[36] Z. Wang, "Clinical study on Xiao'aiping tablets combined with SOX chemotherapy in the treatment of gastric cancer," Drugs \& Clinic, vol. 33, no. 11, pp. 2958-2962, 2018.

[37] Z. Li, "Clinical observation for the combination of Xiao'aiping and chemotherapy on treating elderly advanced gastric cancer," The Medical Forum, vol. 21, no. 4, pp. 418-419, 2017.

[38] W. Shi, "The effect of Xiao'aiping tablet on the control of acute adverse reactions in patients with gastric cancer during chemotherapy," Guide of China Medicine, vol. 15, no. 8, pp. 195-196, 2017.

[39] G. Liu, "Effect of Zhenqifuzheng granule combined with chemotherapy on immune function of patients with advanced gastric cancer and its clinical efficacy and safety," Systems Medicine, vol. 4, no. 11, pp. 25-28, 2019.

[40] J. Wei, "Clinical observation of Zhenqifuzheng granule combined with chemotherapy in the treatment of gastric cancer," Strait Pharmaceutical Journal, vol. 27, no. 7, p. 148, 2015.

[41] S. Hu, H. Dong, S. Tu et al., "Clinical study on effect of Zhenqi Fuzheng granule combined with chemotherapy in treating gastric cancer," China Pharmacist, vol. 8, no. 9, pp. 761-763, 2005.

[42] K. Li and X. Zhang, "Clinical research of Zhenqifuzheng granule combined with Tegafur gimeracil oteracil potassim capsule in treating advanced carcinoma of the gastric cardia in aged patients," Chinese Journal of Geriatrics, vol. 33, no. 12, pp. 1314-1316, 2014.

[43] J. Wang, "Network meta-analysis of Chinese herb injection combined with chemotherapy for gastric cancer," Doctoral thesis, Lanzhou University, Lanzhou City, China, 2014.

[44] M. Huang, L. Hu, Y. Zhang et al., "Bayesian network metaanalysis of Chinese herb injection combined with FOLFOX4 chemotherapy for gastric cancer," Pharmacology and Clinics of Chinese Materia Medica, vol. 35, no. 1, pp. 162-166, 2019.

[45] D. Zhang, J. Zheng, M. Ni et al., "Comparative efficacy and safety of Chinese herbal injections combined with the FOLFOX regimen for treating gastric cancer in China: a network meta-analysis," Oncotarget, vol. 8, no. 40, 2017.

[46] Z. Dan, W. Jiarui, W. Kaihuan et al., "Which are the best Chinese herbal injections combined with XELOX regimen for gastric cancer?: a PRISMA-compliant network meta-analysis," Medicine, vol. 97, no. 12, 2018.

[47] Y. Wang, "Pharmacological action of cinobufacini," $\mathrm{Nei}$ Mongol Journal of Traditional Chinese Medicine, vol. 31, no. 1, p. 76, 2012.

[48] X. Yu, J. Chen, H. Li et al., "Anti-tumour effect of Huachansu," Acta Chinese Medicine, vol. 34, no. 6, pp. 1174-1178, 2019.

[49] C. Luo, "Research of effect of Xiaoaiping pill in anti-cancer mutation and anti-tumor," Modern Hospital, vol. 7, no. 9, pp. 31-32, 2007.

[50] H. Wang, J. Shen, and T. Zhang, "Effect of Xiaoaiping tablet combined with conventional chemotherapy on serum TGF- $\alpha$ and VEGF content in patients with gastric cancer," Hainan Medical Journal, vol. 31, no. 2, pp. 181-183, 2020.

[51] K. Wei and J. Du, "Clinical study on the effect of Bazhen granule on trace elements and immune function in patients with a malignant tumour of Qi and blood deficiency," Journal of Fujian University of Traditional Chinese Medicine, vol. 21, no. 2, pp. 11-13, 2011. 